\title{
Easily Prepared Nanobody-horseradish Peroxidase Fusion Protein-based Immunoassay to Detect Antibodies Against Genotype 2 Porcine Reproductive and Respiratory Syndrome Viruses
}

\section{Hong Duan}

Northwest Agriculture and Forestry University

\section{Xu Chen}

Northwest Agriculture and Forestry University

Jiakai Zhao

Northwest Agriculture and Forestry University

Jiahong Zhu

Northwest Agriculture and Forestry University

Guixi Zhang

Northwest Agriculture and Forestry University

Mengnan Fan

Northwest Agriculture and Forestry University

Beibei Zhang

Northwest Agriculture and Forestry University

\section{Xueting Wang}

Northwest Agriculture and Forestry University

\section{Yani Sun}

Northwest Agriculture and Forestry University

\section{Baoyuan Liu}

Northwest Agriculture and Forestry University

En-Min Zhou

Northwest Agriculture and Forestry University

https://orcid.org/0000-0001-8942-013X

Qin Zhao ( $\square$ qinzhao_2004@nwsuaf.edu.cn )

Northwest Agriculture and Forestry University https://orcid.org/0000-0002-8993-7494

\section{Methodology}

Keywords: Nanobody, Nanobody HRP fusion protein, HEK293S cells, Competitive ELISA, genotype 2 PRRSV 
Posted Date: June 8th, 2021

DOl: https://doi.org/10.21203/rs.3.rs-565896/v1

License: (c) (i) This work is licensed under a Creative Commons Attribution 4.0 International License. Read Full License 


\section{Abstract}

Background: Nanobodies are the third generation of genetically-engineered antibodies, possessing advantages of small molecular weight, simple genetic engineering, and low production cost for promising diagnostic application. In this study, a competitive ELISA (cELISA) using nanobody-horseradish peroxidase (HRP) fusion protein was utilized as an ultrasensitive probe for the first time to detect antibodies against genotype 2 porcine reproductive and respiratory syndrome virus (PRRSV). In addition, a platform for easily producing the nanobody-HRP fusion protein against PRRSV was designed and developed.

Results: In the present study, three nanobodies against the PRRSV-N protein were screened by Camel immunization, library construction, and phage display. Subsequently, a recombinant HEK293S cell line stably secreting nanobody-HRP fusion protein against PRRSV-N protein was successfully designed and constructed using the lentivirus transduction assay. Using the cell lines, the fusion protein was easily produced. Then, a novel cELISA was developed using the nanobody-HRP fusion protein for detecting the antibodies against genotype 2 PRRSV in pig sera, exhibiting a cut-off value of $23.19 \%$ and good sensitivity $(100 \%)$, specificity, and reproducibility. The compliance rate of cELISA with a commercial IDEXX ELISA kit was $96.4 \%$. By testing the sequential sera from the challenged pigs, the results showed that the sensitivity of cELISA was higher than the commercial IDEXX ELISA kit. In addition, the commercial IDEXX ELISA kit can be combined with the developed cELISA for the differential detection of antibodies against genotype 1 and 2 PRRSV in pig sera.

Conclusions: By screening the three nanobodies against the genotype 2 PRRSV-N protein, a recombinant HEK293S cell line stably secreting nanobody-HRP fusion protein against PRRSV-N protein was developed (Scheme 1a). Subsequently, a cELISA was developed for detecting the antibodies against genotype 2 PRRSV using the fusion protein and demonstrated high sensitivity, specificity, and reproducibility (Scheme 1b). More importantly, the production of the fusion protein using the developed platform is simple and low cost.

\section{Introduction}

Nowadays, conventional polyclonal and monoclonal antibodies are widely used as indispensable reagents for the development of disease diagnostic kits [1]. Nevertheless, the traditional antibodies have some shortcomings that limit their application in related fields. For example, polyclonal antibodies suffer from batch-to-batch variability, while monoclonal antibodies have high costs and difficult genetic manipulation for production. Thus, there is an urgent need to develop strategies aimed at the production of alternative scaffolds [2]. In recent years, single-domain antibodies (sdAbs), also known as nanobodies, are derived from the heavy chain antibody variable region $(\mathrm{VHH})$ in camelids and are universally preferred over traditional antibodies [3]. Compared with traditional antibodies, nanobodies exhibit more attractive features for diagnostic application, such as small volume (15 kDa), easy genetic manipulation, and high stability [4-9]. Recently, nanobodies have been fused with horseradish peroxidase (HRP) for the 
development of competitive ELISA (cELISA) to detect antibodies against some animal disease viruses $[10,11]$. However, the production of the nanobody-HRP fusion protein needs to transfect the HEK293T cell with the plasmid each time, which impedes mass production of the diagnostic kit using the nanobodyHRP fusion protein as reagents.

Porcine reproductive and respiratory syndrome (PRRS), caused by PRRS virus (PRRSV), is a major disease threatening large-scale pig farms and is characterized by reproductive disorders in sows and respiratory diseases of pigs of all ages, especially piglets [12]. Currently, PRRSV continues to cause considerable economic loss to the global pig industry, specifically, the United States loses approximately US\$600 million annually due to the virus [13]. PRRSV is an enveloped RNA virus, positive-stranded, belonging to the genus Arterivirus, family Arteriviridae, order Nidovirales [14]. It contains at least 10 open reading frames (ORFs), including ORF1a, ORF1b, ORF2a, ORF2b, ORF3, ORF4, ORF5, ORF5a, ORF6 and ORF7 $[15,16]$. PRRSV is divided into two types based on genetic distances: genotype 1 (European) and genotype 2 (North American) [17, 18]. Particularly, the genotype 2 PRRSV strains are the predominant pathogens that cause clinical outbreaks of PRRS in North America and China [19]. However, the genotype 1 PRRSV has attracted increasing attention, and multiple strains have been recently isolated and identified in China $[19,20]$. These two genotypes share only approximately $60 \%$ nucleotide identities and do not produce cross-protection [21]. The capsid protein of PRRSV (PRRSV-N protein) encoded by ORF7 gene is relatively conserved and accounts for $20 \%-40 \%$ of the total amount of viral particle. It has good antigenicity and immunogenicity, and anti-PRRSV-N protein antibodies can be detected at 7 days postinfection [22, 23]. Therefore, the PRRSV-N protein is an ideal target for the development of a diagnostic kit for detecting anti-PRRSV antibodies [22]. To date, the main commercial ELISA kits for detecting antiPRRSV antibodies in pig sera are developed with indirect ELISA (iELISA) using PRRSV-N protein as a coated antigen [24] and goat anti-pig IgG as the second antibody. However, this method requires a higher purity antigen and an enzyme-labeled secondary antibody, resulting in a large production cost of the commercial kit.

In the present study, the specific nanobodies against PRRSV-N protein were screened and isolated. Based on the nanobodies, a simple and fast platform for synthesizing nanobody-HRP fusion proteins was designed and developed. Then, using the nanobody-HRP fusion proteins as a reagent, a cELISA was developed for detecting anti-genotype 2 PRRSV antibodies in pig sera. The simple operation and low-cost production of nanobody-HRP fusion proteins as an ultrasensitive probe appears to be a promising tool for developing other diagnostic kits for various diseases.

\section{Materials And Methods}

\section{Ethics statement}

The animal studies were carried out in strict accordance with the recommendations in the Guide for the Care and Use of Laboratory Animals of the Northwest Agriculture and Forestry University (NWAFU). The animal protocols were approved by the IACUC of NWAFU (20190017/08). 


\section{Cells, viruses, and sera}

Human embryonic kidney cells (HEK293T) and African green monkey kidney cells (MARC-145) cells were cultured in Dulbecco's Modified Eagle's Medium (DMEM; Life Technologies Corp, Grand Island, NY, USA) supplemented with $10 \%$ fetal bovine serum (FBS, Gibco, Carlsbad, CA, USA) and $1 \%$ antibiotic-antimycotic (Life Technologies Corp) at $37{ }^{\circ} \mathrm{C}$ under $5 \% \mathrm{CO}_{2}$. HEK293S cells were cultured in the commercial serumfree medium (BasalMedia, Shanghai, China) supplemented with $1 \%$ antibiotic-antimycotic (Life Technologies Corp) at $37^{\circ} \mathrm{C}$ and $130 \mathrm{rpm}$ under $5 \% \mathrm{CO}_{2}$.

Genotype 2 PRRSV strains SD16 (GenBank ID: JX087437), NADC30-like (GenBank ID: KX766379) and genotype 1 strain GZ11-G1 (GenBank ID: KF001144) were propagated and titrated in MARC-145 cells in DMEM supplemented with 3\% FBS.

The 217 negative sera for anti-PRRSV antibodies were obtained from the healthy pigs and were verified to be negative via a commercial ELISA kit (IDEXX, Westbrook, ME, USA). Serum samples from the pigs challenged with PRRSV HuN4, SD16, and CH-1R strains were used to evaluate the cELISA assay [25-27]. To determine the coincidence rate of cELISA, 381 challenged sera samples were collected from our previous animal experiments $[28,29]$. Meanwhile, 450 clinical sera samples were collected from various farms in Shandong and detected using both the commercial ELISA kit and cELISA.

\section{Animal experiments}

Nine four-week-old piglets were obtained from a PRRS-free farm and tested for negative PRRSV via the detection of real-time RT-PCR and anti-PRRSV antibodies [30,31]. The piglets were randomly divided into three groups (3 pigs per group), which were separately raised in different isolation rooms. Group 1 piglets were intranasally administered with $1 \times 10^{6.5} \mathrm{TCID}_{50}$ of PRRSV NADC30-like strain, group 2 with $2 \times 10^{5}$ TCID $_{50}$ of PRRSV GZ11-G1 strain, and group 3 with $2 \mathrm{~mL}$ MARC- 145 cell culture supernatant as the negative control. Serum samples were collected at $0,1,3,5,7,10,14,21$ and 28 days post-inoculation (dpi) then used for the detection of antibodies against PRRSV-N protein by cELISA and a commercial IDEXX ELISA kit.

\section{Bactrian camel immunization and library construction}

A four-year-old male Bactrian camel was immunized subcutaneously with the killed PRRSV (CH1a strain) with six times [32]. Every two weeks, the camel was immunized once and after six immunizations, the serum samples from the Bactrian camel was collected and detected for anti-PRRSV antibodies using iELISA. Four days after the last immunization, peripheral blood mononuclear cells (PBMCs) were isolated from $200 \mathrm{~mL}$ blood sample by Leucosep ${ }^{\circledR}$ tubes (Greiner Bio-One, Frickenhausen, Germany). Total RNA was extracted from the $1 \times 10^{7}$ PBMCs and reverse transcribed into cDNA. Then, the Camellidae heavy chain-only antibodies $(\mathrm{VHH})$ genes were amplified using the cDNA as a template by nested PCR, as described previously [33]. The first PCR products ( $700 \mathrm{bp}$ ) amplified with the CALL001 and CALL002 primers (Table 1) were purified according to the instructions of the EasyPure Quick Gel extraction kit 
(TransGen Biotech, Beijing, China). The second PCR with primers VHH-FOR and VHH-REV (Table 1) was amplified using the first purified PCR products as the template. The final purified PCR products ( $400 \mathrm{bp})$ were ligated into the phagemid vector pMECS with Not I and Pst I enzymes sites by T4 DNA ligase (NEB, Ipswich, MA, USA). Then, the ligation products were electro-transformed into competent $E$. coli TG1 cells. Cells were cultured on LB agar plates with $2 \%$ glucose and $100 \mu \mathrm{g} / \mathrm{mL}$ ampicillin at $37^{\circ} \mathrm{C}$ overnight. Subsequently, the bacterial colonies were scraped from the plates, re-suspended in phosphate buffer saline (0.01 M PBS, $\mathrm{pH}$ 7.2) to prepare the VHH phage library against PRRSV, and stored at $-80^{\circ} \mathrm{C}$.

Table 1

Primers used in this study

\begin{tabular}{|c|c|c|}
\hline Primers & Sequence $\left(5^{\prime}-3^{\prime}\right)$ & Usage \\
\hline CALL001 & GTCCTGGCTGCTCTTCTACAAGG & \multirow[t]{4}{*}{ Overlap-VHH } \\
\hline CALL002 & GGTACGTGCTGTTGAACTGTTCC & \\
\hline VHH-FOR & CAGGTGCAGCTGCAGGAGTCTGGGGGAGR & \\
\hline VHH-REV & CTAGTGCGGCCGCTGAGGAGACGGTGACCTGGGT & \\
\hline PRRSV-N-F & CGCGGATCCATGCCAAATAACAACGGCAAGC & \multirow[t]{2}{*}{ pET28a-PRRSV-N } \\
\hline PRRSV-N-R & CCCAAGCTTTCATGCTGAGGGTGATGCTGTG & \\
\hline $\mathrm{Nb}-\mathrm{F}$ & AACTGCAGATGGAGACCGACACC & \multirow[t]{2}{*}{ pCMV-N1-Nbs-HRP } \\
\hline $\mathrm{Nb}-\mathrm{R}$ & ATAAGAATGCGGCCGCTTAGTGGTGATGGTG & \\
\hline \multicolumn{3}{|c|}{ Note: Restriction sites are underlined } \\
\hline
\end{tabular}

The ORF7 gene encoding the PRRSV-N protein was amplified using an infectious PRRSV cDNA clone pBAC-SD16 as the template [34]. The PCR products were purified and cloned into the PET-28a prokaryotic expression vector (Novagen, Darmstadt, Germany). After sequencing, the recombinant positive plasmid was named pET28a-N. The primers of PCR amplification are listed in Table 1. After the pET28a-N plasmids were transformed into E. coli BL21 (DE3) (TransGen Biotech, Beijing, China), the recombinant PRRSV-N protein was expressed and purified based on the previous descriptions [35]. Briefly, the positive bacteria were induced with $0.1 \mathrm{mM}$ isopropyl- $\beta$-thiogalactopyranoside (IPTG) for $6 \mathrm{~h}$ at $37^{\circ} \mathrm{C}$. The bacteria were collected and re-suspended in Buffer $\mathrm{A}(20 \mathrm{mM}$ Tris, $300 \mathrm{mM} \mathrm{NaCl}, \mathrm{pH}$ 7.2-7.4). The supernatant of bacterial solution was collected after the induced bacteria were ultrasonicated and centrifuged.

Subsequently, the supernatant containing recombinant PRRSV-N protein was purified using a Ni-NTA column (Roche, Mannheim, Germany) and eluted with Buffer B (20 mM Tris, $300 \mathrm{mM} \mathrm{NaCl}$, and $250 \mathrm{mM}$ imidazole, $\mathrm{pH}$ 7.2-7.4). Finally, the expression, purification, and antigenicity of the recombinant PRRSV-N protein were analyzed by SDS-PAGE and Western blot with the positive pig sera for PRRSV. 


\section{Screening and identification of PRRSV-N specific nanobodies}

The PRRSV-N protein specific nanobodies were screened by three rounds of panning using phage display technology, as previously described, with the following modifications [32]. Briefly, the VHH phage library was rescued via M13K07 helper phage. The 96-well plates (Nunc, Denmark) were coated with the recombinant PRRSV-N protein ( $4 \mu \mathrm{g} /$ well) overnight at $4^{\circ} \mathrm{C}$ for the three rounds of panning. The coated plates were blocked with $200 \mu \mathrm{L}$ of $2.5 \%$ skim milk at $37^{\circ} \mathrm{C}$ for $1 \mathrm{~h}$ and washed with $0.05 \%$ PBS'T ( $1 \mathrm{~L}$ PBS with $0.5 \mathrm{~mL}$ Tween-20). Then, the above rescued recombinant phage $\left(5 \times 10^{11} \mathrm{pfu} / \mathrm{mL}\right)$ were added to the plates and incubated at room temperature (RT) for $1 \mathrm{~h}$. After the plates were washed again, the binding phages were eluted using $100 \mu \mathrm{L} 0.1 \mathrm{M}$ trimethylamine (Sigma, St. Louis, MO, USA) and neutralized with same volume of $1 \mathrm{M}$ Tris- $\mathrm{HCl}(\mathrm{pH}$ 7.4). Subsequently, the growth log phase of $E$. coli TG1 was infected with the eluted phages and amplified for further rounds of selection. The enrichment of specific phage particles was analyzed using anti-M13/HRP conjugate ELISA combined with phage titration after three rounds of panning. Finally, the 96 colonies were picked randomly and induced with IPTG (1 mM) to express soluble VHHs with an HA-Tag. These recombinant VHHs-HA-Tag proteins were extracted and tested for their capacity to recognize the PRRSV-N protein using iELISA with an anti-HA-Tag antibody as the first antibody (GenScript, Biotech Corp, China). Finally, the positive clones were sequenced, and the nanobodies were grouped according to the hypervariable complementary-determining region 3 (CDR3) sequence.

\section{Establishment of HEK293S cell lines stable expression of nanobody-HRP fusion protein}

To select the best nanobody to construct the stably expressed cells for producing the nanobody-HRP fusion protein, the different fusion proteins were first expressed with transient transfection. The recombinant plasmids were constructed based on the previous descriptions [10, 36]. The VHH gene was amplified using primers $\mathrm{Nb}-\mathrm{F}$ and $\mathrm{Nb}-\mathrm{R}$ (Table 1) with pMECS-VHH plasmid as the template. Then, the PCR products and PCMV-N1-HRP vector were both digested via the Pst I and Not I enzymes and ligated with T4 ligation enzymes to create the recombinant pCMV-N1-Nbs-HRP plasmids. Next, the HEK293T cells were transfected with the recombinant plasmids to produce the nanobody-HRP fusion proteins using polyetherimide ( $\mathrm{PEI}$, Warrington, USA) agents. The cell supernatant containing nanobody-HRP fusion proteins were collected after transfection for 60-72 $\mathrm{h}$. The cELISA procedure was used to select the best nanobody, which is described below. The highest percent competitive inhibition (PI) values of the nanobody-HRP fusion protein were select for constructing the stably expressing cells.

The platform of HEK293S cell line stably expressing the nanobody-HRP fusion proteins was designed as following: the secreting signal sequence, an $\mathrm{HA}$ tag, $\mathrm{VHH}, \mathrm{HRP}$ and His tag sequence were obtained from the pCMV-N1-Nbs-HRP with the digestion of enzymes EcoR I and BamHI. Then, the gene was ligated into pLVX-IRES-ZsGreen lentivirus vector digested with the same two enzymes. To produce lentivirus particles, the HEK293T cells were co-transfected with pLVX-IRES-ZsGreen-Nb-HRP, psPAX2 and pMD2.0G plasmids 
using X-tremeGENE HP DNA Transfection Reagent (Roche, Basel, Switzerland) according to the manufacturer's instructions. After transfection for $60 \mathrm{~h}$, the packaging lentivirus was observed under a fluorescence microscope, and the cell culture supernatant was collected. HEK293S cells were transduced using the above recombinant lentiviruses and supplemented with $10 \mu \mathrm{g} / \mathrm{ml}$ of PolyBrene (Sigma, St. Louis, MO, USA). After $48 \mathrm{~h}$, the transduced cells were observed under a fluorescence microscope. Then, HEK293S cells with green fluorescence were sorted by High-speed sorting flow cytometer (BD, US).

\section{Biological activity analysis of nanobody-HRP fusion proteins produced by the two systems}

The biological activity (titres and stability) of nanobody-HRP fusion proteins produced by the transient transfection and stable expressing system were compared. Firstly, the titers of the nanobody-HRP fusion proteins from the two systems were tested with direct ELISA using a checkerboard titration. Different amounts of the PRRSV-N protein, i.e. 100, 200, 400, and $800 \mathrm{ng} /$ well, were coated into the 96 -well plates, and the different dilution ratios of the nanobody-HRP fusions $(1: 10,1: 100,1: 500$, and 1:1000) were tested. The titer was assessed when the $\mathrm{OD}_{450 \mathrm{~nm}}$ value of the direct ELISA was 1.0 , and the stability of the fusion proteins produced by the two systems was also evaluated. The two methods were independently repeated five times for producing the fusion proteins. Then, the fusion proteins from the different production batches were detected using direct ELISA with a 1:100 dilution. Subsequently, the stability of fusion proteins from the stable expression system was tested from the second, forth, sixth, eighth, and tenth generations and the supernatants from these generations were detected using direct ELSIA with dilutions of 1:10, 1:100, and 1:1000. In addition, the operations of the two systems were compared based on the procedures for producing the fusion proteins.

\section{Development of competitive ELISA using nanobodyHRP fusion proteins for detecting anti-PRRSV antibodies}

The cELISA was developed using the nanobody-HRP fusion proteins as a probe according to a reported procedure [10]. Firstly, the optimal amount of antigen and dilution of fusion protein were determined using a checkerboard titration test with direct ELISA. Different amounts of the PRRSV-N protein $(100,200$, 400 , and $800 \mathrm{ng} /$ well) were coated into the 96 -well plates, then the dilution ratios of fusion proteins of $1: 10,1: 100,1: 500,1: 1000$ were tested. Finally, the optimal amount of antigen and fusions were selected when the $O D_{450 \mathrm{~nm}}$ value of the direct ELISA was 1.0 and the amount of coated antigen was the lowest. Secondly, the optimal dilution ratio of pig sera was determined. Five separate positive and negative pig sera were diluted at 1:10, 1:20,1:40,1:80, and 1:160 and tested with the cELISA. The optimal serum dilution was determined according to the smallest ratio of $\mathrm{OD}_{450 \mathrm{~nm}}$ values between the positive and negative sera $(P / N)$. Finally, the times of incubation and color reaction after the addition of tetramethylbenzidine (TMB) were separately optimized. The incubation times of the mixtures containing the nanobody-HRP fusions and the positive or negative sera with coated PRRSV-N protein were tested at 20, 30, and $40 \mathrm{~min}$. After incubation, TMB was added to color and tested after 10, 15, and $20 \mathrm{~min}$. The 
smallest ratio of $\mathrm{OD}_{450 \mathrm{~nm}}$ values between the positive and negative sera was selected as the optimal incubation and colorimetric reaction times.

After optimizing the above conditions, cELISA was performed as follows. (1) The 96-well ELISA plate was coated with the optimal amount of PRRSV-N recombinant protein and incubated overnight at $4^{\circ} \mathrm{C}$. (2) The plate was blocked with $200 \mu \mathrm{L} 2.5 \%$ (w/v) non-fat dry milk in PBS'T at room temperature (RT) for $1 \mathrm{~h}$ after washed three times with PBS'T. (3) After washed with PBS'T again, each well was added into $100 \mu \mathrm{L}$ of testing mixtures containing the optimal dilutions of serum sample and nanobody-HRP fusions in $2.5 \%$ $(w / v)$ non-fat dry milk, then incubated for optimal times at RT. (4) After the plate was washed again in the same way, TMB (100 $\mu \mathrm{L} /$ well) was added and incubated for optimal times at RT. (5) Finally, $3 \mathrm{M} \mathrm{H}_{2} \mathrm{SO}_{4}$ $\left(50 \mu \mathrm{L} /\right.$ well) was used to stop the colorimetric reaction, and the $\mathrm{OD}_{450 \mathrm{~nm}}$ values were read using an automated ELISA plate reader (Bio-Rad, USA).

\section{Determination of cut-off value, sensitivity, specificity and repeatability of the cELISA}

The PI values were calculated with following formula: $\mathrm{PI}(\%)=\left[1-\left(\mathrm{OD}_{450 \mathrm{~nm}}\right.\right.$ value of testing serum sample $/ O D_{450 \mathrm{~nm}}$ value of negative sample)] $\times 100 \%$. The 217 negative pig serum samples for antiPRRSV antibodies were used to determine the cut-off value. After these sera were detected using the developed cELISA, the cut-off value was calculated by the mean PI of 217 negative serum samples plus 3 standard deviations to ensure $99 \%$ confidence for the negative sera samples within this range [37].

The sensitivity of cELISA was evaluated by testing sera from the different dpi of the three challenged NADC30-like PRRSV pigs as well as the 164 PRRSV-clinical positive sera confirmed by the commercial ELISA kit. In addition, double dilutions (from 1:10 to 1:5120) of five positive pig sera for anti-PRRSV antibodies were tested using cELISA to determine the lowest detection dilution.

The specificity of the cross-competing assay was assessed between the nanobody-HRP fusions and antibodies against other swine viruses, including porcine parvovirus (PPV), porcine circovirus type 2 (PCV2), porcine pseudorabies virus (PRV), transmissible gastroenteritis virus (TGEV), porcine epidemic diarrhea virus (PEDV), and swine influenza virus (SIV). Standard positive sera for anti-the other swine viruses antibodies were confirmed by the commercial ELISA kit. Total 164 PRRSV-clinical negative sera were also tested with the cELISA. To further confirm whether cELISA can detect anti-genotype 1 PRRSV antibodies, the sera from the pigs pre- and post-challenged with GZ11-G1 strain (genotype 1) were tested. Meanwhile, the sera samples from the pigs challenged with HuN4, SD16, and CH-1R strains of genotype 2 PRRSV strains were evaluated to determine whether cELISA can detect antibodies against different genotype 2 PRRSV isolates.

To determine the reproducibility of cELISA, eight separate positive and negative clinical pig serum samples were tested and used to perform the intra-assay and inter-assay variabilities. The inter-assay variation (between plates) and intra-assay variation (within a plate) were evaluated by the coefficient of 
variation (CV). Each sample was tested using three different plates to determine the inter-assay CV, while three replicates within each plate were used to calculate the intra-assay CV [38].

\section{Comparisons of competitive ELISA with commercial ELISA kit}

To evaluate the coincidence of cELISA with the commercial ELISA kit, 381 serum samples from challenged pigs with PRRSV and 450 clinical pig serum samples were tested with each method and analyzed via SPSS software. Among these sera, the results reveal inconsistencies between the two detection methods for these, thus IFA verification was subsequently performed.

\section{Statistical analysis}

Statistical analysis was performed using GraphPad Prism version 5.0 (GraphPad Software, San Diego, CA, USA). Student's $t$-test and Kappa index values were calculated to estimate the platform for HEK293S cell lines stably expressing nanobody-HRP fusion protein, as well as the coincidence between cELISA and the commercial ELISA kit. Repeatability was assessed using CV (CV = SD/Mean), where a CV value less than $15 \%$ for the intra-plate assay was considered an acceptable repeatability level for the assay. These calculations were performed using SPSS software (Version 20, http://www.spss.com.cn).

\section{Results}

\section{Expression and purification of the recombinant PRRSVN protein.}

SDS-PAGE analysis showed that the recombinant PRRSV-N protein was successfully expressed in soluble form with the expected size of $17 \mathrm{kDa}$ (Fig. 1a). In addition, the high purity of the target protein was obtained with the Ni-resin purification (Fig. 1a). To further identify the expression and antigenicity of the target protein, the results of Western blot indicate that the recombinant PRRSV-N protein can react with the positive pig sera for anti-PRRSV antibodies (Fig. 1b). The purified recombinant PRRSV-N protein was used as the coating antigens to screen specific nanobodies and develop the cELISA.

\section{Screening and identification of anti-PRRSV-N protein specific nanobodies}

A phage display $\mathrm{VHH}$ library consisting of approximately $3.2 \times 10^{8}$ individual colonies was constructed from PBMCs of the immunized camel. Positive rate analysis by colony PCR revealed that $96 \%$ of these colonies contained a correct insert corresponding to the size of $\mathrm{VHH}$ genes. Then, 50 randomly clones were selected, sequenced, and analyzed. The results show that each clone was manifested to contain a distinct VHH sequence (data not shown), suggesting the good diversity and high quality of the library. 
After three rounds of biopanning, the specific VHHs phage particles against PRRSV-N protein were enriched (Table 2). 96 mono-clones were randomly selected and expressed periplasmic extracts from the third round of screening for further iELISA detection. The results reveal that 36 individual colonies were identified for specific binding to the PRRSV-N protein (Fig. 2a). Subsequently, the above 36 colonies were sequenced, and three different PRRSV-N specific nanobodies were screened based on the amino acid sequence classification of the CDR3 hypervariable region (named PRRSV-N-Nb1, -Nb2, and -Nb3). The deduced amino acid sequences of the three nanobodies were aligned with the human VH sequence, for which the numbering and CDRs follow the method described by Kabat et al. [39]. Alignment results suggest that PRRSV-N-Nb1 and -Nb2 have typical hydrophilic amino acid substitutions in the framework2 regions Val37, Gly44, Leu45, and Trp47 (located on the VH-VL interface region of VHs) (Fig. 2b). In addition, iELISA results showed that the three nanobodies could specifically bind to recombinant PRRSV$\mathrm{N}$ protein but could not cross-react with the NDV-NP recombinant protein (Fig. 2c). Rather, the recombinant NDV-NP protein was expressed using the same vector pET-28a, which also had a $6 \times$ His-Tag, excluding the possibility that these nanobodies might recognize the $6 \times \mathrm{His}$ region. Moreover, the titres of the periplasmic extracts of PRRSV-N-Nb1 and -Nb2 were higher than that of PRRSV-N-Nb3 (Fig. 2d).

Table 2

Enrichment of nanobodies against PRRSV-N protein specific phages during three rounds of panning.

\begin{tabular}{|lllll|}
\hline Round of panning & $\begin{array}{l}\text { Phage input } \\
\text { (PFU/Well) }\end{array}$ & $\begin{array}{l}\text { Phage output } \\
\text { (PFU/Well) }\end{array}$ & Recovery rate & Enrichment \\
\hline 1st round & $5 \times 10^{10}$ & $5.3 \times 10^{5}$ & $1.06 \times 10^{-5}$ & 8.5 \\
\hline 2nd round & $5 \times 10^{10}$ & $1.9 \times 10^{6}$ & $3.8 \times 10^{-5}$ & $4.0 \times 10^{1}$ \\
\hline 3rd round & $5 \times 10^{10}$ & $1.75 \times 10^{8}$ & $3.5 \times 10^{-3}$ & $7.0 \times 10^{3}$ \\
\hline
\end{tabular}

\section{HEK293S cell lines for stable expression of PRRSV-N- $\mathrm{Nb} 1 \mathrm{HRP}$ fusion protein}

For transient expression, the recombinant plasmids, pCMVNb1HRP, -Nb2-HRP and -Nb3-HRP, were successfully constructed and transfected into the HEK293T cells. An empty vector was used as a control. The results of Western blot and direct ELISA reveal that the PRRSV-Nb1-HRP, -Nb2-HRP, and -Nb3-HRP fusion proteins were successfully expressed in the form of secretion (Fig. 3a and b). The three fusions can specifically bind to the PRRSV-N protein (Fig. 3c), indicating that the fusions do not change the antigenic reaction of the nanobody. However, the titres of the supernatant containing the PRRSV-N-Nb1HRP and -Nb2-HRP fusion proteins were significantly higher than that of PRRSV-N-Nb3-HRP (Fig. 3b). Therefore, the PRRSV-N-Nb1-HRP and -Nb2-HRP fusion proteins were chosen to further evaluate cELISA. Compared with the two fusions blocked by the positive pig sera for anti-PRRSV antibodies to bind the antigen, cELISA results indicate that the blocking rate of PRRSV-N-Nb1-HRP was higher than that of 
PRRSV-N-Nb2-HRP (Fig. 3d). Therefore, PRRSV-N-Nb1 was selected to construct the stably expressed cells for producing the PRRSV-N-Nb1-HRP fusion protein and for further development of cELISA.

In order to conveniently and quickly produce fusion proteins, the HEK293S cell lines stably expressing PRRSV-N-Nb1HRP fusion proteins were successfully established. The positive recombinant HEK293S cells were observed under a fluorescence microscope (Fig. 3e), then the cell supernatant was collected and analyzed for the antigenic activity of PRRSV-N-Nb1-HRP fusion proteins using cELISA. As shown in Fig. 3f, the stably expressed fusion proteins from the HEK293S cells can be still blocked to bind the antigens by the positive sera, which is consistent with the expression by transient transfection.

\section{Comparisons of the two platforms of transient transfection and stable expression}

Compared with the transient transfection system, titers of the PRRSV-N-Nb1-HRP fusion protein from the recombinant HEK293S cell lines were higher (Fig. 4a). In addition, with $100 \mathrm{ng} /$ well PRRSV-N protein, the $\mathrm{OD}_{450 \mathrm{~nm}}$ value was approximately 1.0 with the dilution of 1:100 for the fusion from stably expressed cells

(Fig. 4a). However, the $\mathrm{OD}_{450 \mathrm{~nm}}$ value reached 1.0 at $200 \mathrm{ng} /$ well of coated antigens with the same dilution for the transient transfection (Fig. 4a). The two systems were independently repeated five times. Although significant differences were observed for the three independent experiments of the transient transfection system, no significant difference was noted for stably expressed cells (Fig. 4b). This suggests a greater stability of the expressed recombinant HEK293S cell lines than the transient system. Moreover, the recombinant HEK293S cell lines for stable expression of PRRSV-N-Nb1-HRP fusion protein could be passed continuously for 8 generations with no difference in titers (Fig. 4C).

In the procedure of the stable expression system producing PRRSV-N-Nb1-HRP fusion proteins, cells were cultured for $48 \mathrm{~h}$ then the supernatant was collected for direct used (Fig. 4e). However, the transient transfection system required plating, while plasmids were extracted for each time then transfected into cells. After 48-72 h of transfection, the supernatant was collected for direct use. This production cycle took approximately $132 \mathrm{~h}$ (Fig. 4d), and the system required extra costs for the plasmid extraction kit and transfection reagent. The operation procedures of the two platforms indicate that the stably expressed platform is less complex and less costly than the transient transfection system.

\section{Competitive ELISA using the PRRSV-N-Nb1HRP fusion proteins as reagents}

The optimal concentration of coated PRRSV-N proteins was determined to be $100 \mathrm{ng} / \mathrm{well}$, and the optimal dilution of PRRSV-N-Nb1HRP fusion proteins was identified as 1:100 using a checker board titration assay (Table 3). The optimal dilution of the tested pig serum sample was determined as 1:20 based on the different dilutions of 5 positive and negative sera producing the lowest P/N (Table 4). The optimized incubation time of the sera and PRRSV-N-Nb1-HRP fusion protein mixtures was found to be 30 min, and the optimal colorimetric reaction time was 15 min (Table 5). 
Table 3

Optimized amount of PRRSV-N protein as the coating antigen and dilution of PRRSV-N-Nb1-HRP fusion protein using the direct ELISA.

\begin{tabular}{|llllll|}
\hline Nb1-HRP & \multicolumn{5}{l}{ OD $_{450}$ values after different antigen coating concentration $(\mu \mathrm{g} / \mathrm{mL})$} \\
\cline { 2 - 6 } & $\mathbf{8 . 0}$ & $\mathbf{4 . 0}$ & $\mathbf{2 . 0}$ & $\mathbf{1 . 0}$ & $\mathbf{0}$ \\
\hline $1: 10$ & 3.339 & 3.206 & 3.08 & 2.421 & 0.051 \\
\hline $1: 100$ & 2.915 & 2.653 & 1.724 & 1.021 & 0.081 \\
\hline $1: 500$ & 1.235 & 0.987 & 0.712 & 0.48 & 0.072 \\
\hline $1: 1000$ & 0.686 & 0.497 & 0.342 & 0.187 & 0.075 \\
\hline $\begin{array}{l}\text { Note: The optimal amount of PRRSV-N protein and dilution of PRRSV-N-Nb1-HRP were selected when } \\
\text { the OD }\end{array}$ 450nm values of the direct ELISA was approximately 1.0 & \\
\hline
\end{tabular}


Table 4

Optimized dilution of tested pig sera for cELISA.

\begin{tabular}{|c|c|c|c|c|c|c|}
\hline \multirow[t]{2}{*}{ No. Serum } & \multirow[t]{2}{*}{ Sera type } & \multicolumn{5}{|c|}{ Dilutions of the pig serum samples } \\
\hline & & 1:10 & 1:20 & 1:40 & 1:80 & 1:160 \\
\hline \multirow[t]{3}{*}{1} & Positive & 0.12 & 0.15 & 0.24 & 0.28 & 0.52 \\
\hline & Negative & 1.07 & 1.14 & 1.05 & 1.18 & 1.23 \\
\hline & $\mathrm{P} / \mathrm{N}$ & 0.11 & 0.13 & 0.23 & 0.24 & 0.42 \\
\hline \multirow[t]{3}{*}{2} & Positive & 0.17 & 0.21 & 0.33 & 0.49 & 0.87 \\
\hline & Negative & 1.06 & 1.13 & 1.07 & 1.09 & 1.23 \\
\hline & $\mathrm{P} / \mathrm{N}$ & 0.16 & 0.18 & 0.31 & 0.45 & 0.71 \\
\hline \multirow[t]{3}{*}{3} & Positive & 0.14 & 0.17 & 0.28 & 0.37 & 0.61 \\
\hline & Negative & 1.07 & 1.13 & 1.18 & 1.20 & 1.18 \\
\hline & $\mathrm{P} / \mathrm{N}$ & 0.13 & 0.15 & 0.24 & 0.31 & 0.52 \\
\hline \multirow[t]{3}{*}{4} & Positive & 0.10 & 0.12 & 0.22 & 0.23 & 0.44 \\
\hline & Negative & 1.07 & 1.13 & 1.15 & 1.13 & 1.15 \\
\hline & $\mathrm{P} / \mathrm{N}$ & 0.10 & 0.10 & 0.19 & 0.20 & 0.38 \\
\hline \multirow[t]{3}{*}{5} & Positive & 0.12 & 0.15 & 0.26 & 0.31 & 0.53 \\
\hline & Negative & 1.10 & 1.17 & 1.15 & 1.15 & 1.15 \\
\hline & $\mathrm{P} / \mathrm{N}$ & 0.11 & 0.13 & 0.22 & 0.26 & 0.46 \\
\hline
\end{tabular}


Table 5

Optimal competition time of the mixture containing sera and PRRSV-N-Nb1-HRP fusion proteins incubated with the antigen and colorimetric reaction using a checkerboard assay with cELISA.

\begin{tabular}{|c|c|c|c|}
\hline \multirow[t]{2}{*}{ Times of color reaction (min) } & \multicolumn{3}{|c|}{ Incubation time (min) of antigens, sera and PRRSV-Nb1-HRP fusions } \\
\hline & 20 & 30 & 40 \\
\hline \multirow[t]{3}{*}{10} & 0.103 & 1.031 & 1.077 \\
\hline & 0.057 & 0.165 & 0.173 \\
\hline & 0.551 & 0.160 & 0.160 \\
\hline \multirow[t]{3}{*}{15} & 0.103 & 1.066 & 1.103 \\
\hline & 0.057 & 0.168 & 0.183 \\
\hline & 0.550 & 0.158 & 0.166 \\
\hline \multirow[t]{3}{*}{20} & 0.117 & 1.068 & 1.088 \\
\hline & 0.058 & 0.172 & 0.202 \\
\hline & 0.496 & 0.161 & 0.185 \\
\hline
\end{tabular}

To determine the cut-off value of cELISA, the results reveal that the average PI (X) value of 217 negative sera was $2.49 \%$ with an SD of $6.9 \%$. The cut-off value of cELISA was determined to be $23.19 \%(2.49 \%+$ $3 S D$ ). Therefore, the $\mathrm{PI}$ of pig serum sample $\geq 23.19 \%$ is considered positive, while $\mathrm{PI}<23.19 \%$ is negative.

\section{Sensitivity, specificity and reproducibility of the competitive ELISA}

The sera from the pre- and post-challenged pigs with NADC30-like PRRSV and 164 positive clinical serum samples were tested to assess the sensitivity of cELISA. Seropositivity was first observed at $5 \mathrm{dpi}$ in one of the three pigs, and all sera were still positive for anti-PRRSV antibodies until $28 \mathrm{dpi}$ (Fig. 5a). Comparatively, the seropositivity was first observed at $7 \mathrm{dpi}$ with the commercial IDEXX ELISA kit (Fig. 5b). These results suggest a higher sensitivity of cELISA compared to the commercial IDEXX ELISA kit. For the 164 positive clinical serum samples, the PI values of 109 samples were greater than $80 \%$, and only 8 samples had PI values from $23.19-30 \%$ (Fig. 5c). These results indicate that the sensitivity of cELISA for testing clinical pig sera was $100 \%$. For the different dilutions of the 5 positive pig sera using cELISA, sera at a dilution of 1:1280 were negative, and those at 1:320 were positive (Fig. 5d).

To determine the specificity of cELISA, antisera against other swine viruses, including PPV, PCV2, PRV, TGEV, PEDV and SIV, were tested using cELISA, using 6 PRRSV positive sera samples as the positive 
control. According to the results, the PI values of 6 positive serum samples were $79 \%-91 \%$, while the PI values of antisera against other swine viruses were 1\%-19\% (Fig. 6a). Furthermore, the 164 negative sera were detected using the cELISA with PI values ranging 1\%-20\% (Fig. 6b). To further evaluate whether cELISA can test anti-genotype 1 PRRSV antibodies, sera from the pre- and post-challenged pigs with GZ11-G1 strain (genotype 1) were examined. The results reveal that all sera, until $28 \mathrm{dpi}$, were positive via detection with the commercial IDEXX ELISA kit, but all were negative using the developed cELISA (Fig. 6c). Meanwhile, the sera were also tested from the pre- and post-challenged pigs with HuN4, SD16, and $\mathrm{CH}-1 \mathrm{R}$ strains of genotype 2 PRRSV. Accordingly, seropositivity was first observed at $7 \mathrm{dpi}$, and all sera remained positive for anti-PRRSV HuN4, SD16 and CH-1R strains of antibodies until 28 or $21 \mathrm{dpi}$ (Fig. 7d-f). Taken together, these results confirm that the developed cELISA can specifically detect antigenotype 2 PRRSV antibodies.

To analyze the reproducibility of cELISA, eight separate positive and negative clinical serum samples were tested and used to evaluate the intra-assay and inter-assay variabilities. The intra-assay $\mathrm{CV}$ of the PI were analyzed in the range of $0.55 \%-4.64 \%$ with a median value of $2.6 \%$, while the range for the interassay CV was $1.57 \%-9.53 \%$ with a median value of $5.55 \%$ (Table 6). These data indicate that the cELISA method exhibits good reproducibility.

Table 6

Reproducibility of the cELISA determined by $\mathrm{CV} \%$ value of intra and inter assay.

\begin{tabular}{|lll|}
\hline & CV \% value range of 8 serum samples & Median value \\
\hline Intra assay precision (CV\%) & $0.55-4.65$ & 2.6 \\
\hline Inter assay precision (CV\%) & $1.57-9.53$ & 5.55 \\
\hline
\end{tabular}

Note: Intra assay precision: Determined from three repetitions (well-to-well) of 8 serum samples in the same method. Inter assay precision: Determined from three repetitions (plate-to-plate) at different time.

\section{Agreements of competitive ELISA and commercial IDEXX ELISA kit}

To assess the consistency of cELISA, 381 pig sera from the challenged pigs at different dpi (0-28 dpi) were tested with both cELISA and commercial IDEXX ELISA kit. The results of both methods coincided in 378 (205+/173-) of the 381 serum samples with an agreement rate of 99.2\% (Kappa $=0.98$ ). In addition, for the 450 clinical pig sera collected from various farms in Shandong, an agreement rate of $96.4 \%$ (Kappa $=0.82)$ was determined for the two detection methods (Table 7). Statistical analysis further indicates that cELISA had a high level of consistency with the commercial IDEXX ELISA kit, and no significant differences were observed between cELISA and the commercial IDEXX ELISA kit (Kappa values >0.4) (Table 7). Next, the sera with inconsistent results were verified by IFA. The results showed that the three sera with inconsistent results among 381 challenged sera were positive for IFA, positive for cELISA, and negative for the commercial IDEXX ELISA kit (Fig. 7a). As shown in Fig. 7b and c, 16 of 450 
clinical sera had inconsistent results. Among them, four serum samples were positive using cELISA, negative using commercial IDEXX ELISA kit, and positive for IFA (Fig. 7b). The remaining twelve sera were negative for CELISA and positive for the commercial IDEXX ELISA kit, while IFA revealed seven positive sera and five negative sera (Fig. 7c). It can be suggested that the seven serum samples were likely to be genotype 1 PRRSV. While cELISA has a high consistency with the commercial IDEXX ELISA kit, and it exhibits a higher sensitivity, which is promising for clinical testing.

Table 7

Comparisons of the developed cELISA with commercial IDEXX ELISA kit by detecting challenged and clinical pig serum samples.

\begin{tabular}{|c|c|c|c|c|c|c|c|}
\hline \multirow[t]{3}{*}{ Samples } & \multirow[t]{3}{*}{ cELISA } & \multirow[t]{3}{*}{ Number } & \multirow{2}{*}{\multicolumn{2}{|c|}{$\begin{array}{l}\text { Commercial } \\
\text { ELISA Kit }\end{array}$}} & \multirow{3}{*}{$\begin{array}{l}\text { Agreement } \\
(\%)\end{array}$} & \multirow{3}{*}{$\begin{array}{l}\text { Kappa } \\
\text { value }\end{array}$} & \multirow{3}{*}{$\begin{array}{l}\text { Positive } \\
\text { rate }\end{array}$} \\
\hline & & & & & & & \\
\hline & & & + & - & & & \\
\hline \multirow[t]{2}{*}{$\begin{array}{l}\text { Challenged } \\
\text { sera }\end{array}$} & + & $208(A)$ & $\begin{array}{l}205 \\
\text { (B) }\end{array}$ & 3 & \multirow[t]{2}{*}{$99.2 \%$} & \multirow[t]{2}{*}{0.98} & \multirow[t]{2}{*}{$54.6 \%$} \\
\hline & - & $173(\mathrm{C})$ & 0 & $\begin{array}{l}173 \\
\text { (D) }\end{array}$ & & & \\
\hline \multirow[t]{2}{*}{ Clinical sera } & + & $395(A)$ & $\begin{array}{l}391 \\
\text { (B) }\end{array}$ & 4 & \multirow[t]{2}{*}{$96.4 \%$} & \multirow[t]{2}{*}{0.82} & \multirow[t]{2}{*}{$87.8 \%$} \\
\hline & - & $55(C)$ & 12 & $43(\mathrm{D})$ & & & \\
\hline \multicolumn{8}{|c|}{ Agreement $(\%)=(B+D) /(A+C)$} \\
\hline \multicolumn{8}{|c|}{ Positive rate $(\%)=A /(A+C)$} \\
\hline \multicolumn{8}{|c|}{ The kappa value $>0.4$ was regarded as significant difference } \\
\hline
\end{tabular}

\section{Discussion}

The sensitivity and specificity of different ELISA methods can be determined by using antibodies are critical reagents [40]. Despite the use of traditional antibodies, including polyclonal and monoclonal antibodies, for developing ELISA [41], these antibodies have high production costs and require enzyme labelling [42]. In the latest research, nanobodies have acquired increased attention as the smallest known antigen binding antibody with simple genetic manipulation and, thus, as a promising new generation antibody for diagnostic applications [43, 44]. Therefore, nanobody-HRP fusion proteins have been designed and used to develop ELISA for detecting antibodies against different virus. Compared to traditional antibodies for the commercial ELISA kit, the nanobody-HRP fusion protein is simple and inexpensive to produce and does not require purification or enzyme-labelling. In this study, a nanobodyHRP fusion protein against anti-PRRSV-N protein was produced and used for the first time as a probe to develop a cELISA for detecting anti-PRRSV antibodies in pig sera. The procedures were performed according to a previous study but with some modifications [36]. 
In a previous work, a platform was constructed to produce the nanobody-HRP fusion proteins via transient transfection of HEK293T cells. However, the production of the platform was time-consuming, laborious, costly, and not suitable for mass production [10]. To solve these problems, another platform using HEK293S cell lines for stably expressing the nanobody-HRP fusion proteins was constructed in the present study, particularly avoiding the trouble of each transfection. In addition, the titers of nanobodyHRP fusion proteins in the supernatant from the recombinant HEK293S cell lines were found to be than those of the compared transient transfection system. Moreover, produced nanobody-HRP fusion proteins from different batches were stable using the stable expression system. In conclusion, the procedures of the stable expression system are simple and easy for mass production

PRRS is one of the most common and economically-important infectious diseases of swine globally. Clinical signs of PRRS are not characteristic, and sometimes, the course of PRRSV infection is subclinical, thus laboratory detection methods are necessary for diagnosis. At present, ELISA is the most popular method that is also used to monitor the antibody level on a population. Among the available commercial ELISA kits for detecting anti-PRRSV antibodies, the IDEXX PRRS X3 Ab Test is the most widely used and generally recognized as the de facto gold standard [45]. However, this commercial iELISA kit requires the use of a second antibody and, as such, is expensive for mass clinical application. Comparatively, the cELISA based on the nanobody-HRP fusion protein developed in the present study demonstrated simple and low-cost production. In addition, the sensitivity of cELISA is higher than the commercial ELISA kit. More importantly, the developed cELISA has a high agreement with the IDEXX PRRS X3 Ab Test. These advantages suggest that the developed cELISA has a good prospect of market application and promotion.

In the present study, the developed cELISA can detect the antibodies against different genotype 2 PRRSV isolates but not genotype 1 PRRSV. This suggests that the epitope recognized by PRRSV-N-Nb1 may be only located in the $\mathrm{N}$ protein of genotype 2 PRRSV. The homology of the amino acid sequence of the genotype 2 PRRSV N protein ranges between $96 \%-100 \%$ [46], indicating that the assay may detect antibodies against most of the PRRSV genotype 2 strains. In the future, more experiments will be needed to determine the key amino acids of the epitope and to further analyze the epitope of amino acid from different PRRSV isolates. Such study will reveal whether the antibodies against all the genotype 2 PRRSV isolates can be detected by the developed cELISA. According to our knowledge, the commercial IDEXX ELISA kit can detect antibodies against both genotype 1 and 2 PRRSV. Therefore, utilizing this kit following the developed cELISA may be advantageous for the differential diagnoses of genotype 1 and 2 PRRSV.

Although the developed cELISA has simple operation, low production cost, and good sensitivity and specificity, the construction of this platform is highly complicated. Specifically, it requires the immunization of camels, screening of functional nanobodies, and establishing a cell line stably expressing nanobody-HRP fusion proteins. This series of tasks is complicated and demands very skilled experimenters to operate, despite cELISA test only taking $45 \mathrm{~min}$ to run. In short, the establishment of this 
platform is of complicated. Yet, it can be noted that the platform is established successfully, and it becomes very convenient in production and clinical application.

\section{Conclusions}

In the present study, three specific nanobodies against the PRRSV-N protein were screened and identified. Based on these nanobodies, a simple and fast platform for the production of nanobodies-HRP fusion protein was designed. Then, the fusion proteins were utilized as a reagent to develop the cELISA method for detecting anti-genotype 2 PRRSV antibodies in pig sera. The simple operation and low-cost production of nanobody-HRP fusion proteins as an ultrasensitive probe will be a promising tool for developing diagnostic kits for various diseases.

\section{Declarations}

\section{Acknowledgements}

Not applicable.

\section{Authors' contributions}

$H D, E M Z$ and QZ designed the experiments and drew the scheme and figures; HD performed the experiments; XC, JKZ, JHZ, GXZ, MNF, BBZ, XTW, YNS, BYL and EMZ contributed reagents/materials/analysis tools; EMZ and QZ analyzed the data; HD, EMZ and QZ wrote the paper. All authors read and approved the final manuscript.

\section{Funding}

The research is funded by grants from National Key R\&D Program of China (2016YFD0500706) and Tang Scholar of Cyrus Tang Foundation (QZ).

\section{Availability of data and materials}

All data generated or analyzed during this study are included in the article.

\section{Consent for publication}

Not applicable.

\section{Competing interests}


The authors declare that they have no competing interests.

\section{Author details}

${ }^{1}$ Department of Preventive Veterinary Medicine, College of Veterinary Medicine, Northwest A\&F University, Yangling 712100, Shaanxi, China. ${ }^{2}$ Scientific Observing and Experimental Station of Veterinary Pharmacology and Diagnostic Technology, Ministry of Agriculture, Yangling 712100, Shaanxi, China.

\section{References}

1. Liu JK. The history of monoclonal antibody development - Progress, remaining challenges and future innovations. Ann Med Surg (Lond). 2014;3:113-116.

2. Gebauer M, Skerra A. Engineered protein scaffolds as next-generation antibody therapeutics. Curr Opin Chem Biol. 2009;13:245-255.

3. Hamers-Casterman C, Atarhouch T, Muyldermans S, Robinson G, Hamers C, Songa EB, Bendahman N, Hamers R. Naturally occurring antibodies devoid of light chains. Nature. 1993;363:446-448.

4. Muyldermans S. Nanobodies: natural single-domain antibodies. Annu Rev Biochem. 2013;82:775797.

5. Rothbauer U, Zolghadr K, Muyldermans S, Schepers A, Cardoso MC, Leonhardt H. A versatile nanotrap for biochemical and functional studies with fluorescent fusion proteins. Mol Cell Proteomics. 2008;7:282-289.

6. Huang L, Reekmans G, Saerens D, Friedt JM, Frederix F, Francis L, Muyldermans S, Campitelli A, Van Hoof $C$. Prostate-specific antigen immunosensing based on mixed self-assembled monolayers, camel antibodies and colloidal gold enhanced sandwich assays. Biosens Bioelectron. 2005;21:483490.

7. De Meyer T, Muyldermans S, Depicker A. Nanobody-based products as research and diagnostic tools. Trends Biotechnol. 2014;32:263-270.

8. Pruszynski M, Koumarianou E, Vaidyanathan G, Revets H, Devoogdt N, Lahoutte T, Lyerly HK, Zalutsky MR. Improved tumor targeting of anti-HER2 nanobody through N-succinimidyl 4guanidinomethyl-3-iodobenzoate radiolabeling. J Nucl Med. 2014;55:650-656.

9. Lu Q, Li X, Zhao J, Zhu J, Luo Y, Duan H, Ji P, Wang K, Liu B, Wang X, Fan W, Sun Y, Zhou EM, Zhao Q. Nanobodyhorseradish peroxidase and -EGFP fusions as reagents to detect porcine parvovirus in the immunoassays. J Nanobiotechnology. 2020;18:7.

10. Sheng Y, Wang K, Lu Q, Ji P, Liu B, Zhu J, Liu Q, Sun Y, Zhang J, Zhou EM, Zhao Q. Nanobodyhorseradish peroxidase fusion protein as an ultrasensitive probe to detect antibodies against Newcastle disease virus in the immunoassay. J Nanobiotechnology. 2019;17:35.

11. Mu Y, Jia C, Zheng X, Zhu H, Zhang X, Xu H, Liu B, Zhao Q, Zhou EM. A nanobody-horseradish peroxidase fusion protein-based competitive ELISA for rapid detection of antibodies against porcine 
circovirus type 2. J Nanobiotechnology. 2021;19:34.

12. Pejsak Z, Stadejek T, Markowska-Daniel I. Clinical signs and economic losses caused by porcine reproductive and respiratory syndrome virus in a large breeding farm. Vet Microbiol. 1997;55:317322.

13. Du T, Nan Y, Xiao S, Zhao Q, Zhou EM. Antiviral Strategies against PRRSV Infection. Trends Microbiol. 2017;25:968-979.

14. Lunney JK, Fang Y, Ladinig A, Chen N, Li Y, Rowland B, Renukaradhya GJ. Porcine Reproductive and Respiratory Syndrome Virus (PRRSV): Pathogenesis and Interaction with the Immune System. Annu Rev Anim Biosci. 2016;4:129-154.

15. Firth AE, Zevenhoven-Dobbe JC, Wills NM, Go YY, Balasuriya UB, Atkins JF, Snijder EJ, Posthuma CC. Discovery of a small arterivirus gene that overlaps the GP5 coding sequence and is important for virus production. J Gen Virol. 2011;92:1097-1106.

16. Johnson CR, Griggs TF, Gnanandarajah J, Murtaugh MP. Novel structural protein in porcine reproductive and respiratory syndrome virus encoded by an alternative ORF5 present in all arteriviruses. J Gen Virol. 2011;92:1107-1116.

17. Kuhn JH, Lauck M, Bailey AL, Shchetinin AM, Vishnevskaya TV, Bao Y, Ng TF, LeBreton M, Schneider BS, Gillis A, Tamoufe U, Diffo Jle D, Takuo JM, Kondov NO, Coffey LL, Wolfe ND, Delwart E, Clawson AN, Postnikova E, Bollinger L, Lackemeyer MG, Radoshitzky SR, Palacios G, Wada J, Shevtsova ZV, Jahrling PB, Lapin BA, Deriabin PG, Dunowska M, Alkhovsky SV, Rogers J, Friedrich TC, O'Connor DH, Goldberg TL. Reorganization and expansion of the nidoviral family Arteriviridae. Arch Virol. 2016;161:755-768.

18. Adams MJ, Lefkowitz EJ, King AM, Harrach B, Harrison RL, Knowles NJ, Kropinski AM, Krupovic M, Kuhn JH, Mushegian AR, Nibert M, Sabanadzovic S, Sanfacon H, Siddell SG, Simmonds P, Varsani A, Zerbini FM, Gorbalenya AE, Davison AJ. Ratification vote on taxonomic proposals to the International Committee on Taxonomy of Viruses (2016). Arch Virol. 2016;161:2921-2949.

19. Wang X, Yang X, Zhou R, Zhou L, Ge X, Guo X, Yang H. Genomic characterization and pathogenicity of a strain of type 1 porcine reproductive and respiratory syndrome virus. Virus Res. 2016;225:40-49.

20. Chen N, Cao Z, Yu X, Deng X, Zhao T, Wang L, Liu Q, Li X, Tian K. Emergence of novel European genotype porcine reproductive and respiratory syndrome virus in mainland China. J Gen Virol. 2011;92:880-892.

21. Ropp SL, Wees CE, Fang Y, Nelson EA, Rossow KD, Bien M, Arndt B, Preszler S, Steen P, ChristopherHennings J, Collins JE, Benfield DA, Faaberg KS. Characterization of emerging European-like porcine reproductive and respiratory syndrome virus isolates in the United States. J Virol. 2004;78:36843703.

22. Nelson EA, Christopher-Hennings J, Benfield DA. Serum immune responses to the proteins of porcine reproductive and respiratory syndrome (PRRS) virus. J Vet Diagn Invest. 1994;6:410-415.

23. Yoon KJ, Zimmerman JJ, Swenson SL, McGinley MJ, Eernisse KA, Brevik A, Rhinehart LL, Frey ML, Hill HT, Platt KB. Characterization of the humoral immune response to porcine reproductive and 
respiratory syndrome (PRRS) virus infection. J Vet Diagn Invest. 1995;7:305-312.

24. Biernacka K, Podgorska K, Tyszka A, Stadejek T. Comparison of six commercial ELISAs for the detection of antibodies against porcine reproductive and respiratory syndrome virus (PRRSV) in field serum samples. Res Vet Sci. 2018;121:40-45.

25. Li J, Wang G, Yang D, Zhao B, Zhao YP, Liu YG, Cai XH, Nan YC, Zhou EM, Wu CY. Development of luciferase-linked antibody capture assay based on luciferase immunoprecipitation systems for antibody detection of porcine reproductive and respiratory syndrome virus. Bmc Biotechnology. 2018;18:

26. Gao JM, Xiao SQ, Xiao YH, Wang XP, Zhang C, Zhao Q, Nan YC, Huang BC, Liu HL, Liu NN, Lv JH, Du TF, Sun YN, Mu Y, Wang G, Syed SF, Zhang GP, Hiscox JA, Goodfellow I, Zhou EM. MYH9 is an Essential Factor for Porcine Reproductive and Respiratory Syndrome Virus Infection. Scientific Reports. 2016;6:

27. Li ZJ, Wang G, Wang Y, Zhang C, Huang BC, Li QY, Li LL, Xue BY, Ding PY, Cai XH, Wang CB, Zhou EM. Immune responses of pigs immunized with a recombinant porcine reproductive and respiratory syndrome virus expressing porcine GM-CSF. Vet Immunol Immunopathol. 2015;168:40-48.

28. Wang G, Yu Y, Tu Y, Li Y, Tong J, Zhang C, Liu Y, Li A, Jiang C, Wang S, Tao Y, Cai X. Characterizing the thymic lesions in piglets infected with attenuated strains of highly pathogenic porcine reproductive and respiratory syndrome virus. Vet Immunol Immunopathol. 2015;168:258-261.

29. Wang G, Li L, Yu Y, Tu Y, Tong J, Zhang C, Liu Y, Li Y, Han Z, Jiang C, Wang S, Zhou EM, He X, Cai X. Highly pathogenic porcine reproductive and respiratory syndrome virus infection and induction of apoptosis in bone marrow cells of infected piglets. J Gen Virol. 2016;97:1356-1361.

30. Chen NH, Ye MX, Xiao YZ, Li S, Huang YC, Li XD, Tian KG, Zhu JZ. Development of universal and quadruplex real-time RT-PCR assays for simultaneous detection and differentiation of porcine reproductive and respiratory syndrome viruses. Transboundary and Emerging Diseases. 2019;66:2271-2278.

31. Kashyap SP, Hiremath J, Vinutha S, Patil SS, Suresh KP, Roy P, Hemadri D. Development of recombinant nucleocapsid protein-based indirect enzyme-linked immunosorbent assay for serosurvey of porcine reproductive and respiratory syndrome. Vet World. 2020;13:2587-2595.

32. Vincke C, Gutierrez C, Wernery U, Devoogdt N, Hassanzadeh-Ghassabeh G, Muyldermans S. Generation of single domain antibody fragments derived from camelids and generation of manifold constructs. Methods Mol Biol. 2012;907:145-176.

33. Liu H, Wang Y, Duan H, Zhang A, Liang C, Gao J, Zhang C, Huang B, Li Q, Li N, Xiao S, Zhou EM. An intracellularly expressed Nsp9-specific nanobody in MARC-145 cells inhibits porcine reproductive and respiratory syndrome virus replication. Vet Microbiol. 2015;181:252-260.

34. Wang C, Huang B, Kong N, Li Q, Ma Y, Li Z, Gao J, Zhang C, Wang X, Liang C, Dang L, Xiao S, Mu Y, Zhao Q, Sun Y, Almazan F, Enjuanes L, Zhou EM. A novel porcine reproductive and respiratory syndrome virus vector system that stably expresses enhanced green fluorescent protein as a separate transcription unit. Vet Res. 2013;44:104. 
35. Duan H, Ma ZQ, Xu LL, Zhang AK, Li ZW, Xiao SQ. A novel intracellularly expressed NS5B-specific nanobody suppresses bovine viral diarrhea virus replication. Veterinary Microbiology. 2020;240:

36. Yamagata M, Sanes JR. Reporter-nanobody fusions (RANbodies) as versatile, small, sensitive immunohistochemical reagents. Proc Natl Acad Sci U S A. 2018;115:2126-2131.

37. Charoenchanikran P, Kedkovid R, Sirisereewan C, Woonwong Y, Arunorat J, Sitthichareonchai $P$, Sopipan N, Jittimanee S, Kesdangsakonwut S, Thanawongnuwech R. Efficacy of Fostera(R) PRRS modified live virus (MLV) vaccination strategy against a Thai highly pathogenic porcine reproductive and respiratory syndrome virus (HP-PRRSV) infection. Trop Anim Health Prod. 2016;48:1351-1359.

38. Chaorattanakawee S, Tyner SD, Lon C, Yingyuen K, Ruttvisutinunt W, Sundrakes S, Sai-gnam P, Johnson JD, Walsh DS, Saunders DL, Lanteri CA. Direct comparison of the histidine-rich protein-2 enzyme-linked immunosorbent assay (HRP-2 ELISA) and malaria SYBR green I fluorescence (MSF) drug sensitivity tests in Plasmodium falciparum reference clones and fresh ex vivo field isolates from Cambodia. Malar J. 2013;12:239.

39. Kabat EA, Wu TT. Identical $V$ region amino acid sequences and segments of sequences in antibodies of different specificities. Relative contributions of $\mathrm{VH}$ and $\mathrm{VL}$ genes, minigenes, and complementarity-determining regions to binding of antibody-combining sites. J Immunol. 1991;147:1709-1719.

40. Kohl TO, Ascoli CA. Indirect Competitive Enzyme-Linked Immunosorbent Assay (ELISA). Cold Spring Harb Protoc. 2017;2017:pdb prot093757.

41. Gao Y, Huang X, Zhu Y, Lv Z. A brief review of monoclonal antibody technology and its representative applications in immunoassays. J Immunoassay Immunochem. 2018;39:351-364.

42. Baker M. Reproducibility crisis: Blame it on the antibodies. Nature. 2015;521:274-276.

43. Wang Y, Fan Z, Shao L, Kong X, Hou X, Tian D, Sun Y, Xiao Y, Yu L. Nanobody-derived nanobiotechnology tool kits for diverse biomedical and biotechnology applications. Int J Nanomedicine. 2016;11:3287-3303.

44. Barthelemy PA, Raab H, Appleton BA, Bond CJ, Wu P, Wiesmann C, Sidhu SS. Comprehensive analysis of the factors contributing to the stability and solubility of autonomous human VH domains. J Biol Chem. 2008;283:3639-3654.

45. Sattler T, Wodak E, Revilla-Fernandez S, Schmoll F. Comparison of different commercial ELISAs for detection of antibodies against porcine respiratory and reproductive syndrome virus in serum. BMC Vet Res. 2014;10:300.

46. Meng XJ, Paul PS, Halbur PG, Lum MA. Phylogenetic analyses of the putative M (ORF 6) and N (ORF 7) genes of porcine reproductive and respiratory syndrome virus (PRRSV): implication for the existence of two genotypes of PRRSV in the U.S.A. and Europe. Arch Virol. 1995;140:745-755.

\section{Figures}




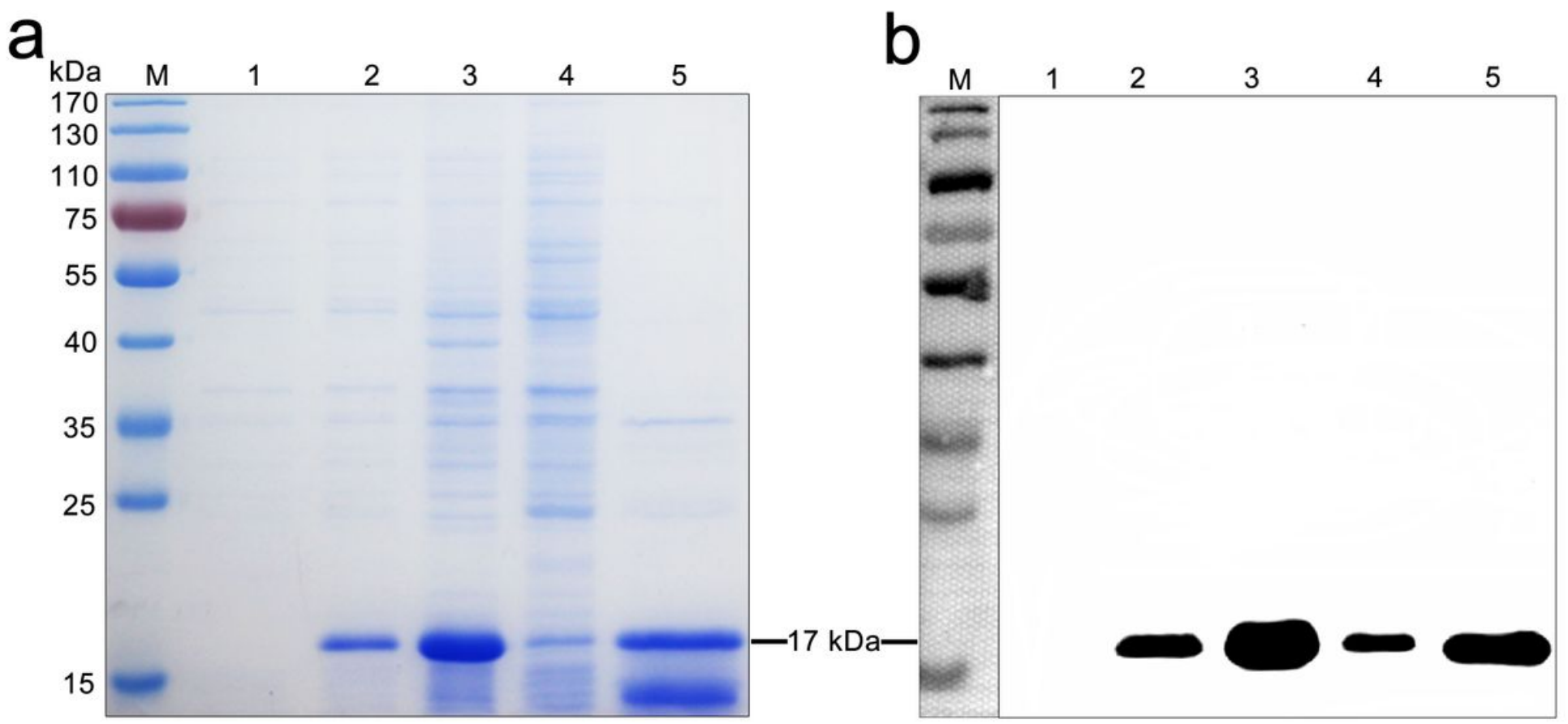

\section{Figure 1}

Expression and purification of recombinant PRRSV-N protein. a SDS-PAGE analysis of the recombinant PRRSV-N protein. $b$ Antigenic analysis of the recombinant PRRSV-N protein using the positive pig sera for PRRSV as first antibody. M: Molecular weight markers; Lane 1: pET28a vector control; Lane 2: Induction with 0.1 mM IPTG; Lane 3: Soluble protein in supernatant after sonication; Lane 4: Inclusion body in precipitation after sonication; Lane 5: Purified PRRSV-N protein. 

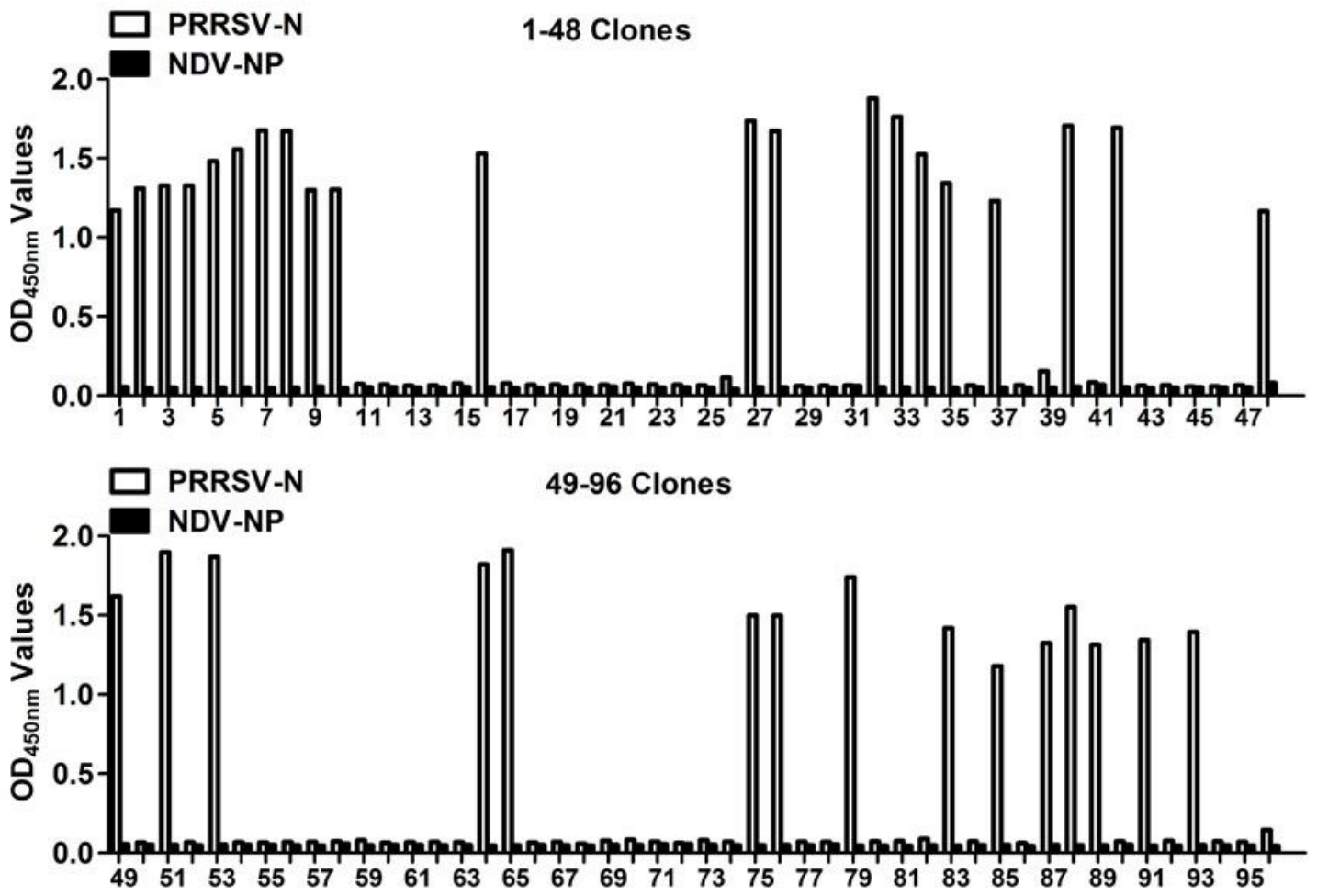

b

Framwork1-

30

40

CDR2-:-

hVH EVHLLESGGNL VQPGGSLRL SCAASGF TFII FVMSWVRQAPGKGLEWVSGVFGSGGNTDYADAVKG PRRSV-N-Nb1QVQL QES GGDSVQVGGSLRL SCAA SGYTFTNYCMAWFRQAPGQEREGVAAI CI GGAGTI YAASVQG PRRSV-N-Nb2QVQL QESGGGSVQA GGSLRL SCTASRYFDNSVPMTWFRQVPGKERE GVACI YFGGGRI DYADSVKG PRRSV-N-Nb3QV QL QES GGDSV QA GGSLRL SCAVSDL QF GSYCMGW RQAPGKVGGEVASI DVGG- RTKYADSVKG

hVH RF TI TRDNSKNTLYL QMNSL RAEDTAI YYCAKH N-Nb1 RF TI SRNSAKNTLYL QMNSL KPEDTAMYYCATE- GSPGFPFRPDKYNKWGQGTQVTVSS
SR PRRSV-N-Nb1RF TI SRNSA KNTLYL QMNSL KPEDTAMYYCATE- GSP GFPFRPDKYNKWGQGTQVTVSS PRRSV-N-Nb3 RF TVTRDNANNTL YL QMNSL KPEDTF TYV CARG- Y GA GCPRNPSDYAYWGQGTQVTVSS

C

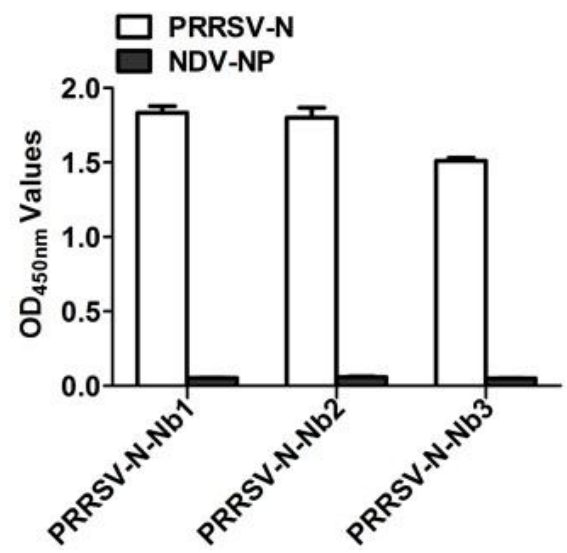

d

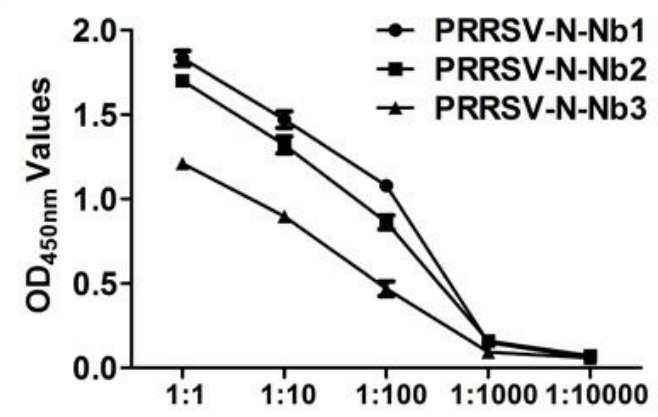

Figure 2

Screening and identification of the nanobodies against the PRRSV N protein. a Identification of the periplasmic extracts from the 96 clones specifically binding to the PRRSV-N protein using iELISA. The 36 clones were positive. $\mathrm{b}$ Amino acid sequence alignment of three nanobodies against PRRSV-N protein with human $\mathrm{VH}$. The hallmark residues at positions $37,44,45$, and 47 are highlighted with a red box. $\mathrm{C}$ Three nanobodies specifically reacted with the PRRSV-N protein using the iELISA. The recombinant NDV- 
NP protein was used as a negative control. $d$ Titration of the nanobodies binding with the PRRSV-N protein in the periplasmic extracts.

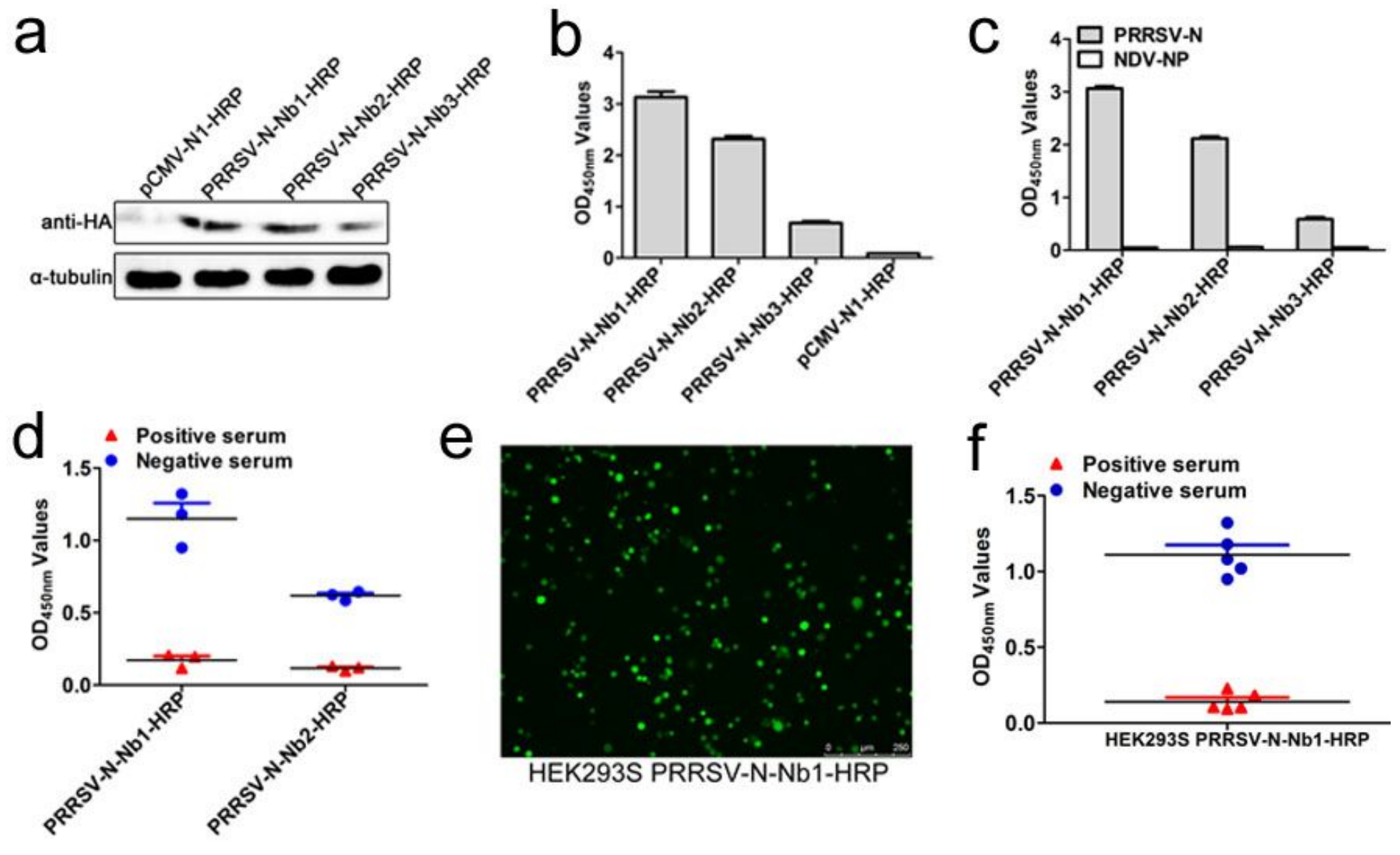

\section{Figure 3}

Establishment of HEK293S cell lines for stable expression of PRRSV-N-Nb1 HRP fusion protein. a Detection of PRRSV-N-Nbs HRP expressed in the HEK293T cells with the anti HA monoclonal antibodies as the first antibody by Western blot. b Detection of the binding between PRRSV-N-Nbs HRP and PRRSV-N using direct ELISA. c Specific reactions between PRRSV-N-Nbs HRP and PRRSV-N using direct ELISA. d Comparisons of the two nanobodies blocking the binding between the pig sera and PRRSV-N protein by cELISA. e Characterization of HEK293S cell lines for stably expressing PRRSV-N-Nb1-HRP by fluorescent microscopy. $f$ Confirmation of the blocking effect of PRRSV-N-Nb1-HRP using the supernatant from the recombinant HEK293S cell lines by cELISA. 

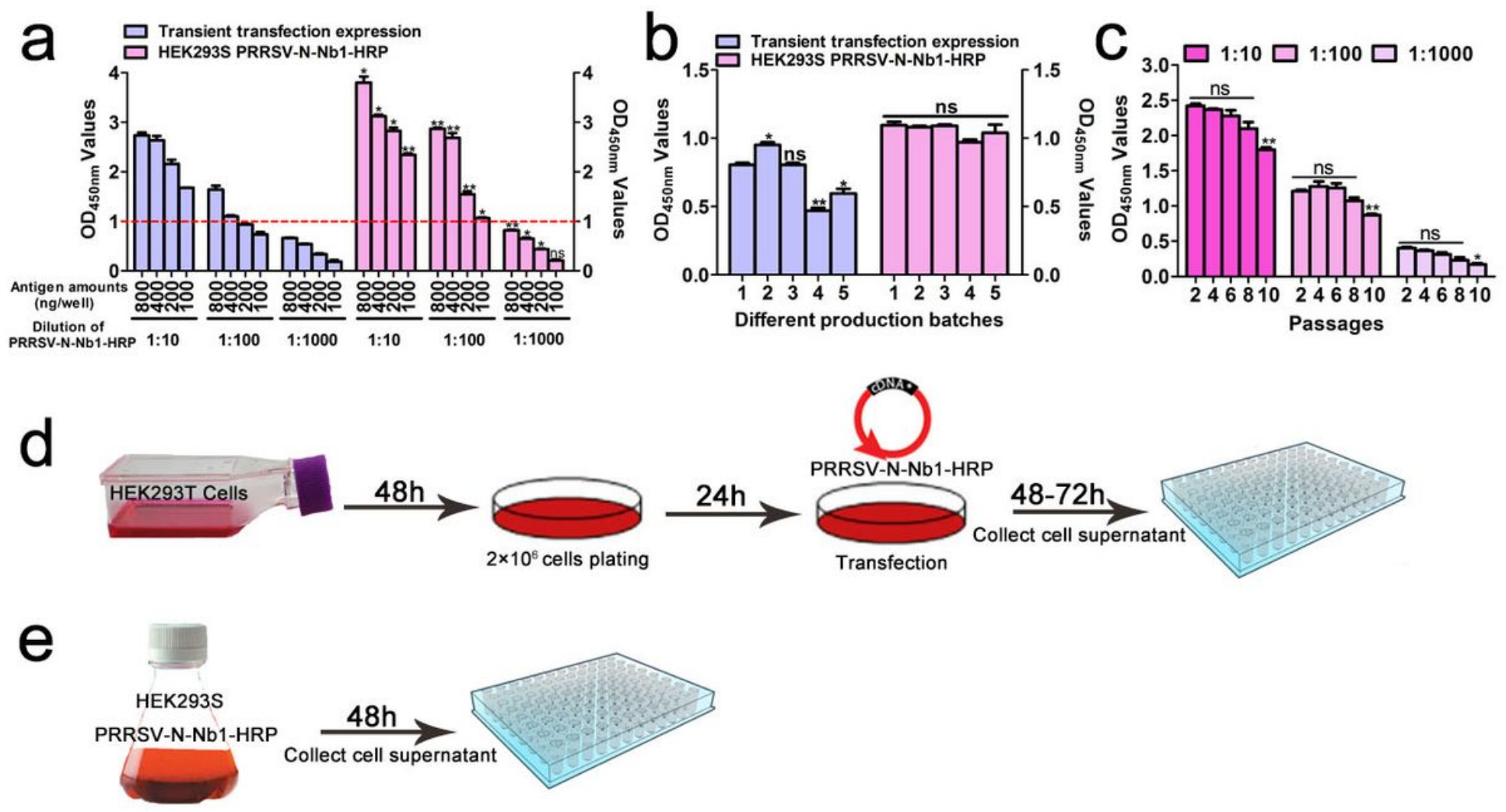

Figure 4

Bioactivity analysis of the PRRSV-Nb1-HRP fusion protein from the stably expressing HEK293S cell lines.

a Expression level of PRRSV-N-Nb1-HRP fusion protein between stable expression in HEK293S and transient transfection in HEK293T cells. b Stability of PRRSV-N-Nb1-HRP fusion protein from the two systems. c Stability of the PRRSV-N-Nb1-HRP fusion protein from the different generations of stably expressing HEK293S cell lines. d Schematic diagram of the production for PRRSV-N-Nb1-HRP fusion proteins using transient transfection in HEK293T cells. e Schematic diagram of the production for PRRSV-N-Nb1-HRP fusion proteins using stable expression in HEK293S cells. 
a

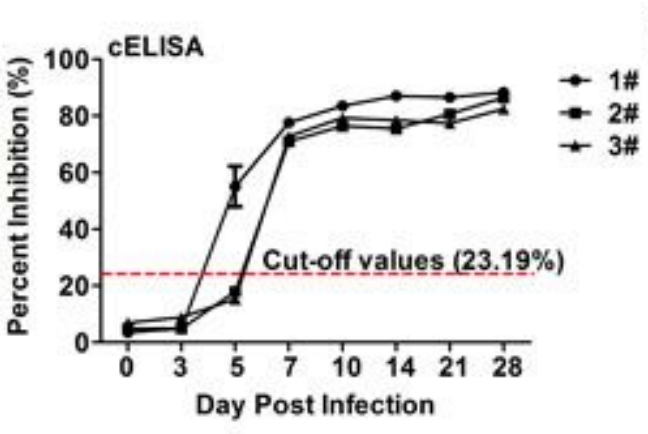

C

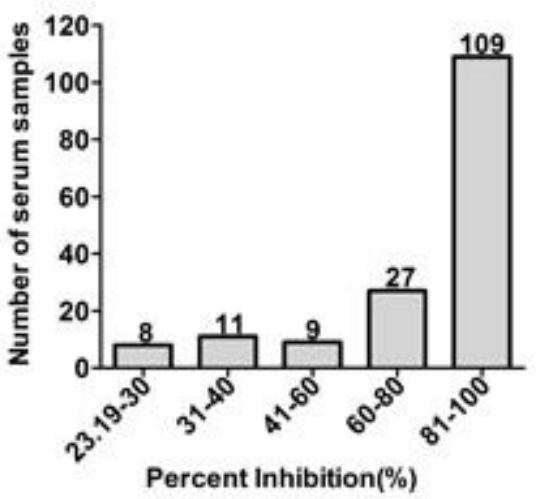

b

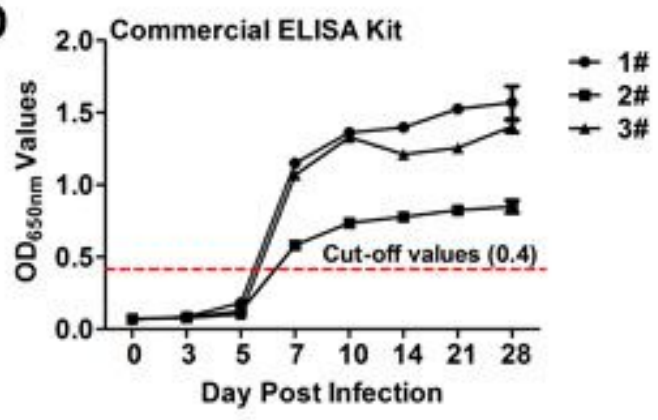

d

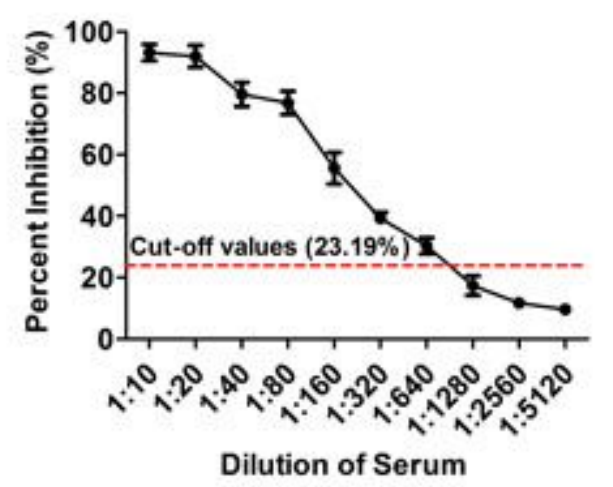

Figure 5

Sensitivity of cELISA using the PRRSV-N-Nb1 HRP fusion protein as a probe. Comparisons of the sensitivity between cELISA (a) and the commercial IDEXX ELISA Kit (b) for detecting the sequential serum samples from the three challenged pigs with NADC30-like strain. c Distribution of the PI values by detecting the clinical positive sera for anti PRRSV antibodies using cELISA. $d$ Determination of the largest dilution of positive pig sera for anti-PRRSV antibodies. 

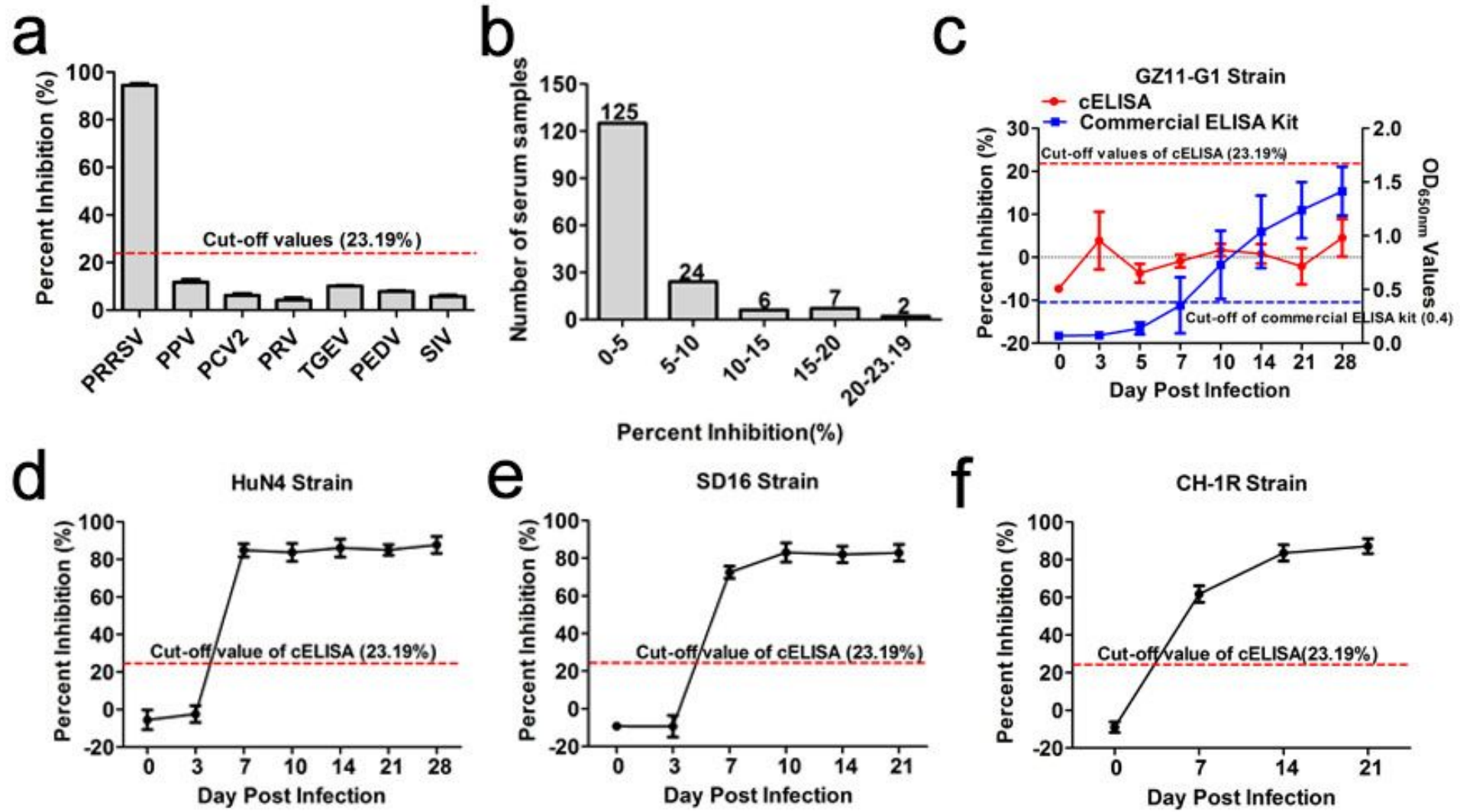

Figure 6

Specificity of cELISA using the PRRSV-N-Nb1 HRP fusion protein as the reagent. a Cross-reaction of cELISA by detecting the antibodies against other swine viruses, including PPV, PCV2, PRV, TGEV, PEDV, and SIV. b Distribution of the PI values by detecting the clinical negative sera for anti PRRSV antibodies using cELISA. Pig serum samples were tested using the cELISA from the challenged pigs with different strains PRRSV, including genotype 1 GZ11-G1 strain (c), HuN4 strain (d), SD16 strain (e), and CH-1R strain (f). 

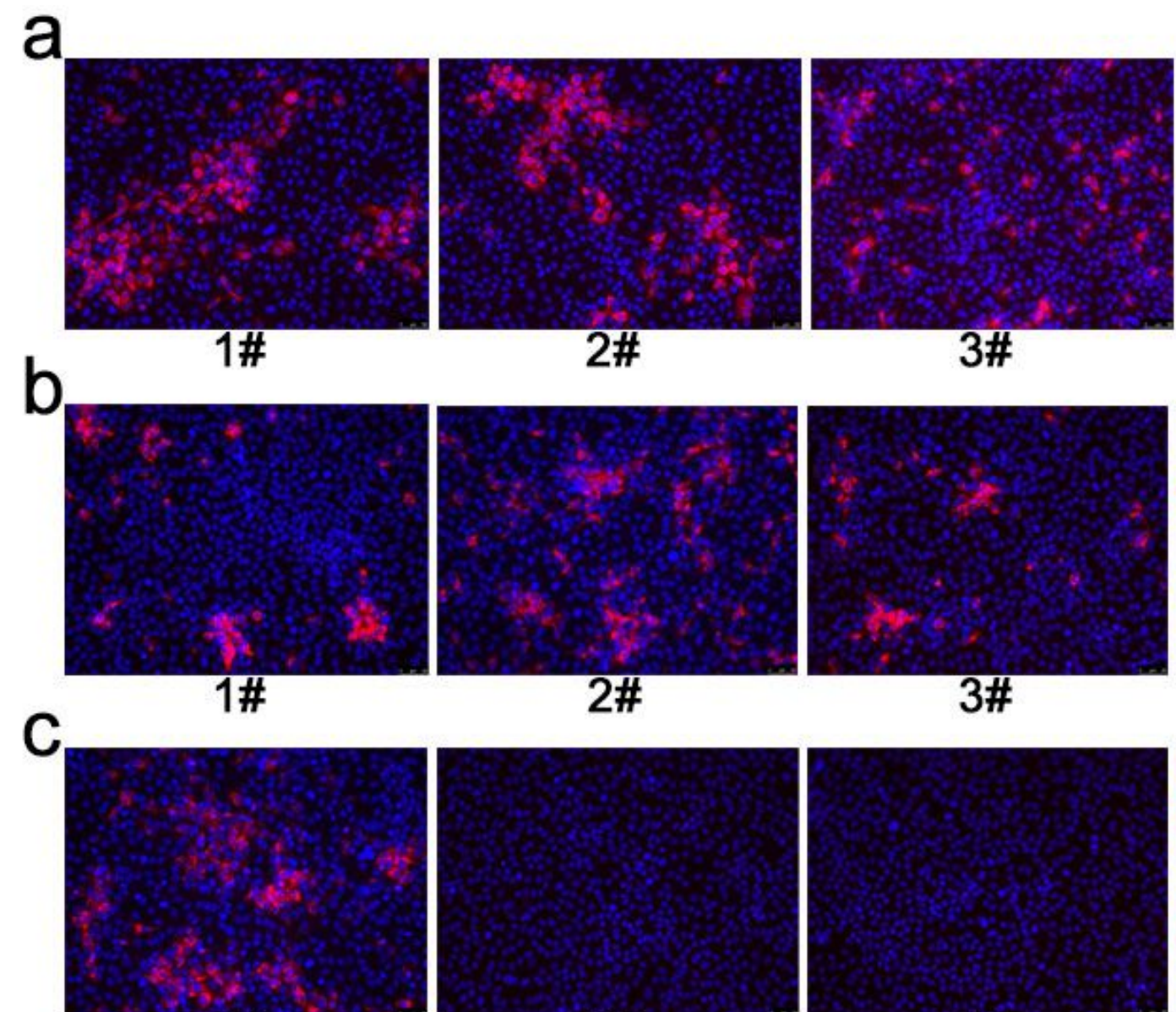

\section{2\#}

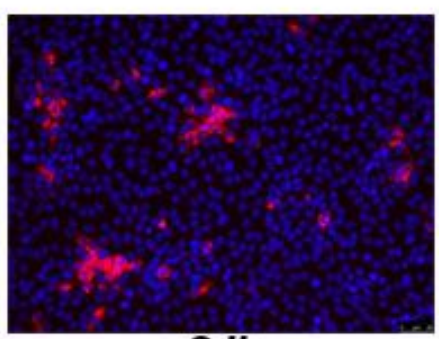

3\#

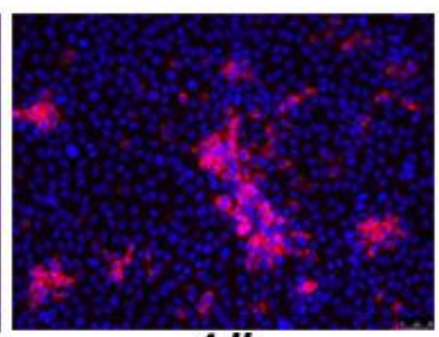

4\#
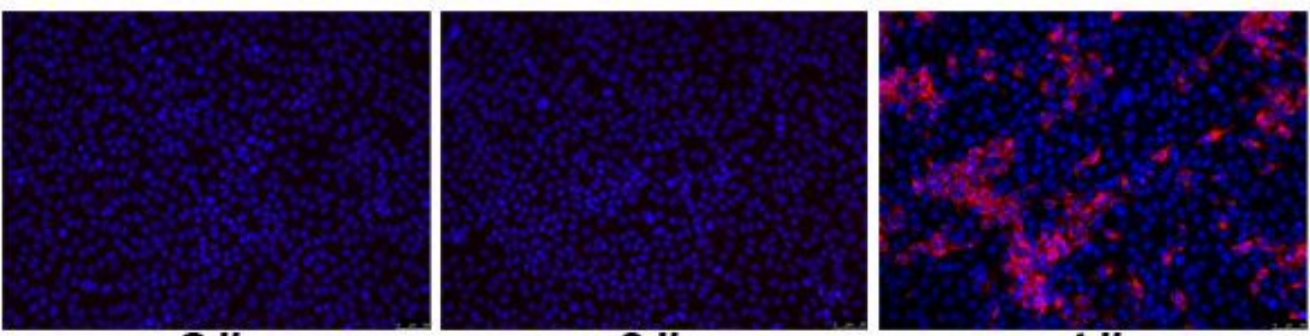

1\#
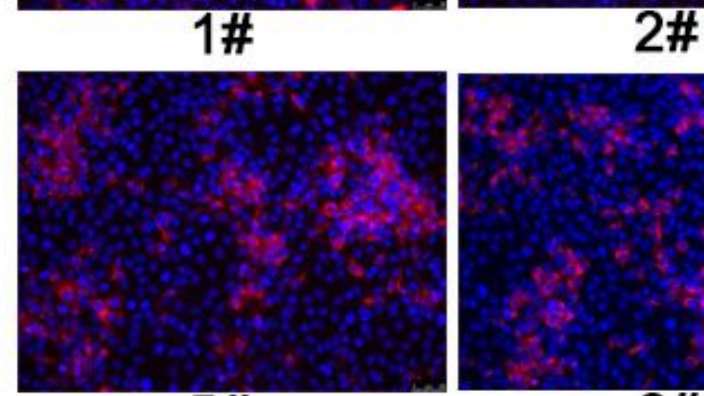

5\#

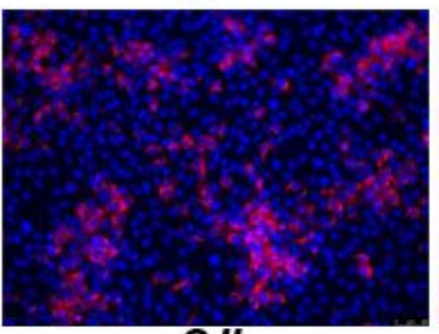

$6 \#$

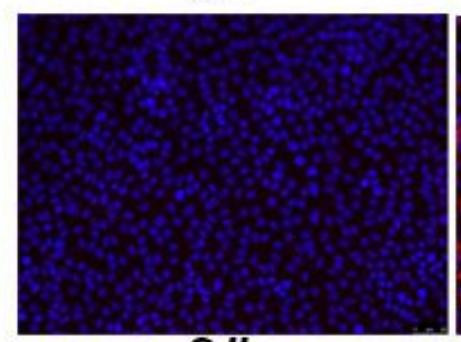

9\#

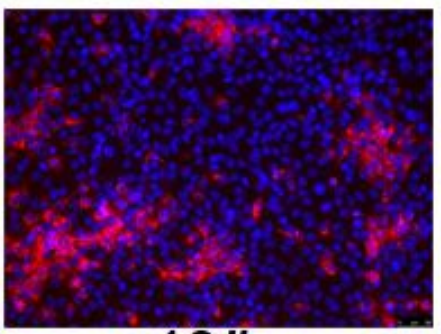

10\#

3\#

4\#

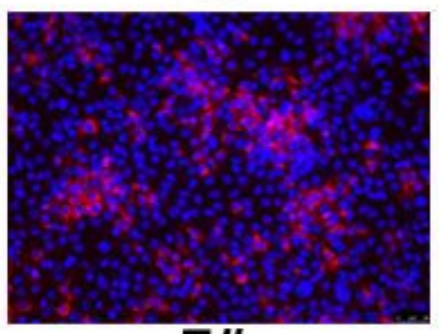

7\#

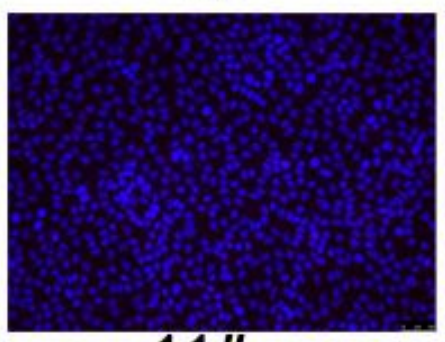

11\#

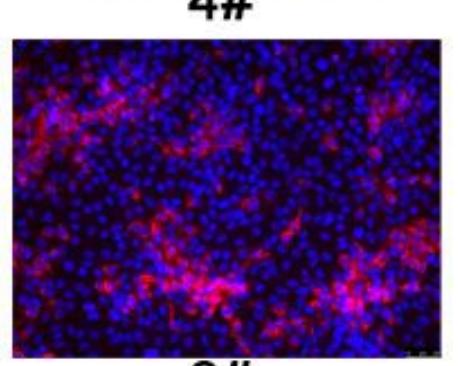

8\#

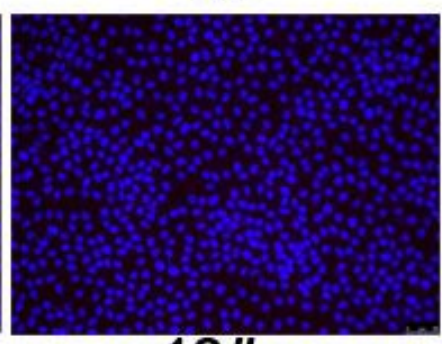

12\#

Figure 7

Detection of the pig serum samples with inconsistent results between the developed cELISA and commercial IDEXX ELISA kit by IFA. a Three inconsistent results from 381 challenged sera were tested by IFA, which were positive for cELISA and negative for the commercial IDEXX ELISA kit. $b$ Four inconsistent results from the clinical pig sera were tested by IFA, which were positive for cELISA and negative for the 
commercial IDEXX ELISA kit. c The remaining twelve sera tested negative using cELISA, but positive using the commercial IDEXX ELISA kit.

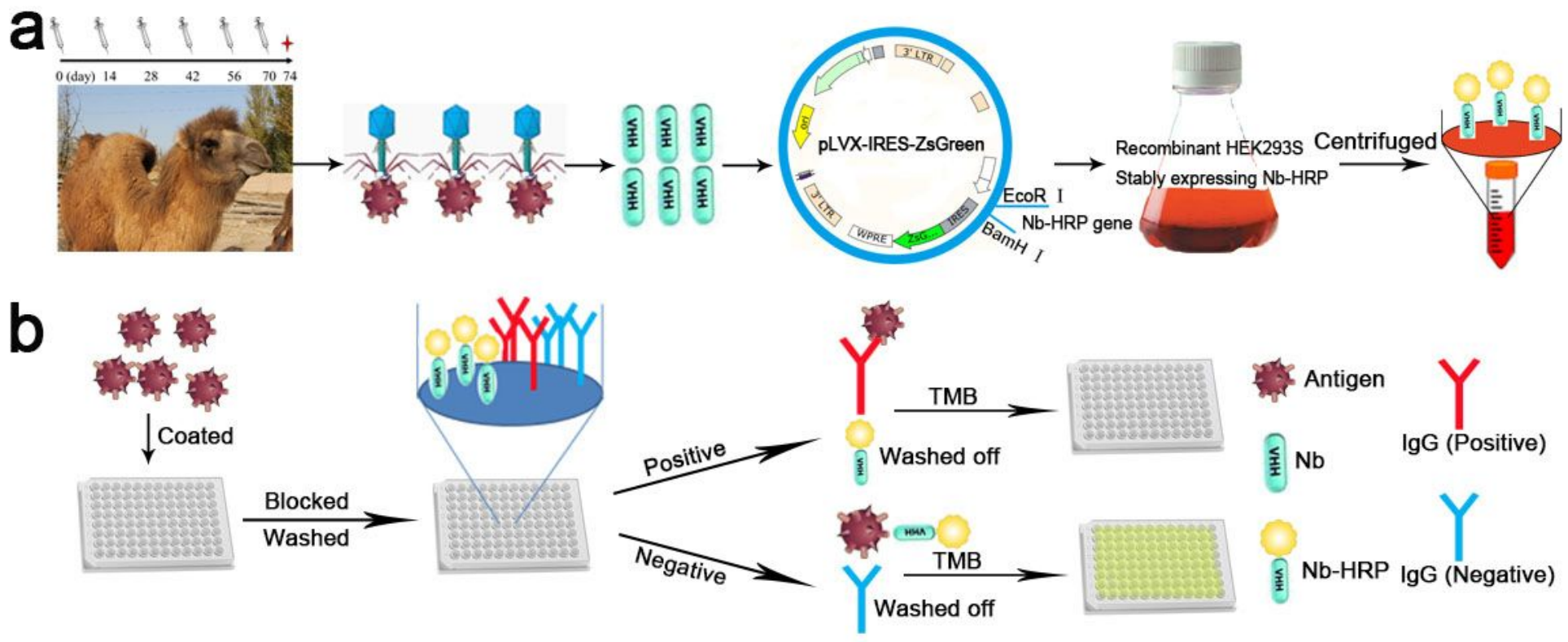

Figure 8

Scheme 1 Schematic representation of developing the cELISA to detect PRRSV antibodies using the nanobody-HRP fusion proteins as a reagent. a The platform for stably expressing nanobody-HRP fusion proteins using HEK293S cells. b Competitive ELISA for using the fusion protein as a reagent. 